\title{
Disaster preparedness in humanitarian logistics: A collaborative approach for resource management in floods
}

Oscar Rodríguez-Espíndola ${ }^{1 *}$, Pavel Albores ${ }^{1}$ and Christopher Brewster ${ }^{2}$

${ }^{1}$ Aston Business School, Aston University, Birmingham, UK.

${ }^{2}$ TNO, Netherlands.

*Corresponding author. Tel. +44 (0) 121204 3558. E-mail address: o.rodriguez-

espindola@aston.ac.uk

\begin{abstract}
The logistical deployment of resources to provide relief to disaster victims and the appropriate planning of these activities are critical to reduce the suffering caused. Disaster management attracts many organisations working alongside each other and sharing resources to cope with an emergency. Consequently, successful operations rely heavily on the collaboration of different organisations. Despite this, there is little research considering the appropriate management of resources from multiple organisations, and none optimising the number of actors required to avoid shortages or convergence.
\end{abstract}

This research introduces a disaster preparedness system based on a combination of multi-objective optimisation and geographical information systems to aid multi-organisational decision-making. A cartographic model is used to avoid the selection of floodable facilities, informing a bi-objective optimisation model used to determine the location of emergency facilities, stock prepositioning, resource allocation and relief distribution, along with the number of actors required to perform these activities.

The real conditions of the flood of 2013 in Acapulco, Mexico, provided evidence of the inability of any single organisation to cope with the situation independently. Moreover, data collected showed the unavailability of enough resources to manage a disaster of that magnitude at the time. The results highlighted that the number of government organisations deployed to handle the situation was excessive, leading to high cost without achieving the best possible level of satisfaction. The system proposed showed the potential to achieve better performance in terms of cost and level of service than the approach currently employed by the authorities.

Keywords: Humanitarian logistics, multiple objective programming, OR in disaster relief, disaster preparedness. 


\section{INTRODUCTION}

During September 2013, Mexico was struck simultaneously by hurricane Ingrid from the Atlantic and hurricane Manuel from the Pacific. This situation affected nearly $77 \%$ of the territory causing extraordinary rainfall and successive flooding in different areas (Pedrozo-Acuña, Breña-Naranjo, \& Domínguez-Mora, 2014). The resulting floods had a major impact in the State of Guerrero. Beyond the estimated damage of 23,441 million pesos (US\$ 1.243 billion), there was a need to shelter around 44,216 people, whilst 105 people were found dead (García, Méndez, Reyes, \& Marin, 2015).

Acapulco represented one of the most affected areas in the State. On the evening of September $15^{\text {th }}$, a press release listed the most vulnerable regions of the country to be affected by the forecasted rainfall, among which Acapulco was classified as having high vulnerability and the highest population amongst the endangered areas (CENAPRED, 2014). Authorities declared a state of emergency from $16^{\text {th }}$ September until $26^{\text {th }}$ November 2013 , spending around 231.3 million pesos (US\$ 12.26 million) in relief aid (García et al., 2015).

Using freedom of information requests (FOI) to contact different government agencies, a total of twelve participants acknowledged their involvement and made information available about the emergency. From them, ten organisations were identified to have actively participated in logistics activities. These organisations worked alongside each other to provide support for disaster victims under the umbrella of the Civil Protection National system (SINAPROC). However, there was evidence of an absence of appropriate planning, preparation and risk analysis in the region for managing these situations (García et al., 2015).

The aim of this research is to develop a system for emergency preparedness considering the management of resources from different organisations. The system uses a combination of geographical information systems (GIS) and optimisation to determine the location of emergency facilities, the stock prepositioning policy, initial relief distribution, and the allocation of material and human resources. The system is able to identify which organisations are required under the circumstances of the emergency to provide tailored operations and prevent material and human convergence and shortages.

This paper is organised as follows. Section 2 introduces relevant concepts for the analysis, whereas Section 3 describes the main contributions in the literature concerning integrated approaches for disaster preparedness. The description and design of the system proposed is explained on Section 4 . Section 5 describes the application of the system to the situation experienced in Acapulco, México, in 2013. The assessment of the model is presented in Section 6, whilst Section 7 discusses the results obtained, and Section 8 introduces the conclusions. 


\section{THEORETICAL FRAMEWORK}

\subsection{Flood preparedness}

Disaster preparedness involves the activities undertaken to prepare a community to react when a disaster takes place (Altay \& Green, 2006). Adequate preparedness can significantly improve disaster response activities. For instance, in India, a major cyclone in 1977 caused a death toll around 20,000 people. After an early warning system, meteorological radars and emergency plans were established, similar cyclones caused considerably lower death tolls (UNISDR, 2009). Preparedness activities have the potential to enhance response and improve operations as long as the context of the disaster is properly considered, because different types of disasters require different types of response (De Leeuw, Vis, \& Jonkman, 2012) given the varying features of each type of hazard.

Hydrological disasters are some of the most frequent and harmful natural disasters (Chang, Tseng, \& Chen, 2007). Nevertheless, these disasters allow more time to react (Kunz \& Reiner, 2012) because these are more easily predicted and prevented than other disasters, making them suitable for the development of preparedness tools (Chang et al., 2007).

Merz and Blöschl (2003) distinguished five types of floods; long-rain floods, short-rain floods, flash floods, rain-on-snow floods and snowmelt floods. This research focuses on the first two types, given that flash floods create local emergencies with small/moderate rainfall depths (Merz \& Blöschl, 2003), whereas the other two types rely on snow conditions which are largely absent in Mexico.

Short-rain floods occur after rainfall of short duration and high intensity, usually saturating part of a local or regional settlement, whereas long-rain floods are caused by several days of low-intensity rainfall exceeding the capacity of the catchment thereby affecting large areas (Merz \& Blöschl, 2003).

Geographic features are relevant for long-rain floods and short-rain floods. Hydrological analysis of regions and basins makes it possible to predict floods using return periods (Ward, de Moel, Aerts, \& Glade, 2011), forecast floods based on rainfall patterns (Esteves, 2013), and generate mapping tools to estimate water heights and damaged zones (Liebscher, Kirschstein, \& Becker, 2012). A tool for flood management can take advantage of these elements using GIS to provide tailored operations.

\subsection{Mexican disaster management framework}

Decision-making in disaster situations in Mexico is centralised, with SINAPROC as the coordinating body for disaster activities among different participants. It links to four main branches: executive coordination, technical coordination, technical support and co-responsibility. The Ministry of Interior manages the executive coordination at three government levels (viz. National, State and Municipal). The technical coordination provides counsel for planning, operation and assessment of disaster management activities, whereas technical support organisations provide aid and advice for specific disasters. Co-responsibility organisations provide support along with human and material resources for emergency activities on top of their normal duties (SEGOB, 2006). According to regulations, a 
total of up to 23 actors are classified as co-responsible for hydro-meteorological disaster events, and they have to be coordinated by SINAPROC to use their resources optimally in order to provide assistance. Evidently, the Mexican system relies on the collaboration of different organisations as a key element for disaster operations.

After a disaster strikes a community the first agency at site should provide aid to the victims, and then local authorities can take over to continue operations. If local authorities can cope with the impact of the disaster they oversee the whole operation, otherwise they have to notify state authorities asking for support. That procedure is repeated until the full resources of SINAPROC are deployed (SEGOB, 2006). The purpose of the process is to use only the resources necessary for each event. However, activating one stratum means activating a large number of agencies, something that can be further improved to make more efficient use of resources.

A clear group of regulations and well-placed financial instruments are evidence of the importance disasters have in Mexican plans. However, Alexander (2015) identified poor performance in some communities. Similarly, problems in logistic activities identified by Santos-Reyes and Beard (2011) after a major flood in Tabasco emphasised the need to strengthen preparedness in the country. Alexander (2015) summarised this, stating "the law lacks the instruments for its application", hinting that the framework for disaster management is there, but the tools required to support it are not.

\section{LITERATURE REVIEW}

\subsection{Logistical activities in disaster preparedness}

Caunhye, Nie, and Pokharel (2012) created a framework for emergency logistics including predisaster and post-disaster operations. Before the disaster strikes, evacuation, stock prepositioning and facility location are of vital importance. Initial distribution has also been studied by several other authors (e.g. Chang et al., 2007; Mete \& Zabinsky, 2010; Naji-Azimi, Renaud, Ruiz, \& Salari, 2012).

Evacuation has been studied independently and combined with facility location, creating a broad body of contributions on the topic (e.g. Bish \& Sherali, 2013; Bretschneider \& Kimms, 2012; Lu, 2013; Nagarajan, Shaw, \& Albores, 2012; Pidd, De Silva, \& Eglese, 1996; Saadatseresht, Mansourian, \& Taleai, 2009; Yi \& Ozdamar, 2007) and it is outside of the scope of this work.

This section introduces articles tackling the synergy between facility location, stock prepositioning and relief distribution. In that category, Campbell and Jones (2011) incorporated risk of facility disruption for one supply point using mathematical equations to determine the optimal stock quantity and the total expected cost associated with deliveries, with an alternative for multiple supply points.

Using chance constraint models, Renkli and Duran (2015) used a scenario-based formulation to minimise the weighted probability of road blockage, whereas Bozorgi-Amiri, Jabalameli, Alinaghian, 
and Heydari (2012) combined uncertainty in supply, demand, transportation and procurement to propose a nonlinear model to minimise the sum of the expected cost and its variance.

There are several papers considering two-stage stochastic models with scenario-based approaches. Considering uncertainty in demand, road network and the conditions after the disaster, Salmeron and Apte (2010) provided a formulation aiming to minimise the expected number of casualties and unmet transfers of population. Incorporating the possibility of destruction of relief, Rawls and Turnquist (2010) introduced unmet demand penalties and holding costs for unused material. That was complemented later on with quality of service constraints (Rawls \& Turnquist, 2011), the inclusion of a dynamic variant of the model (Rawls \& Turnquist, 2012) and the incorporation of a risk measure in total cost (Noyan, 2012). Mete and Zabinsky (2010) designed a model in which the first stage determines the location of warehouses and amount of prepositioned stock by minimising cost, whereas in the second stage a combination between transportation time and unsatisfied demand is minimised to prepare relief distribution. Rennemo, Rø, Hvattum, and Tirado (2014) considered vehicles, the state of the infrastructure and demand as stochastic elements in a dynamic formulation to maximise the combination of demand fulfilment and unused budget. Considering uncertainty in supply, demand and the transportation network, Tofighi, Torabi, and Mansouri (2016) aimed to minimise the cost of stock prepositioning and facility location in the first stage, whereas in the second stage a multi-objective problem focused on relief distribution seeking to minimise total distribution time, the maximum weighted distribution time for critical items, and total cost of unused inventories and unmet demands.

Employing multi-objective optimisation, Abounacer, Rekik, and Renaud (2014) proposed a model looking to minimise transportation time, personnel needed and uncovered demand. Accounting for uncertainty in demand and supply, Bozorgi-Amiri, Jabalameli, and Mirzapour Al-e-Hashem (2011) proposed a two-stage model considering potential destruction of relief. The model minimises the sum of the expected value and variance of the total cost, along with the sum of the maximum shortages. There are studies incorporating GIS in the analysis to manage the uncertainty of the impact of the disaster. Barzinpour and Esmaeili (2014) used the Risk Assessment tool for Diagnosis of Urban Areas against Seismic Disaster for different earthquake scenarios. The information supports a formulation including three objective functions seeking to maximise coverage, minimise location cost and minimise operational cost. Esmaeili and Barzinpour (2014) extended that by considering areas outside of the region. Rodríguez-Espíndola and Gaytán (2015) incorporated a GIS analysis to discard floodable facilities and identify road failures. The model minimises total cost and total distance travelled considering priorities for the most affected areas. 


\subsection{Resource management among multiple actors}

After the earthquake in Haiti in 2010, the government and several relief agencies struggled to get the aid to many people. Even with different organisations and expertise on the field, there was an inability to deliver aid because of the lack of trucks (Holguín-Veras, Jaller, \& Wachtendorf, 2012).

Logistics decisions rely on having the required resources to perform activities efficiently. In largescale disasters, the resources needed are usually provided by the joint participation of different stakeholders (Nolte, Martin, \& Boenigk, 2012). Providing guidance for them is not a trivial issue. Currently, however, emergency logistics articles are designed as if there is only one organisation owning all the required resources.

Disaster preparedness plans ought to consider the participation of different organisations to resemble the circumstances in reality and to become enablers for coordination. Coordination is understood as "the cooperation of independent units for the purpose of eliminating fragmentation, gaps in service delivery, and unnecessary (as opposed to strategic) duplication of services" (Gillespie, 1991).

Coordination is a widely known challenge in disaster management (Auf der Heide, 1989). For disaster management, some of the reasons underpinning those challenges are;

- Involvement of several actors (Balcik, Beamon, Krejci, Muramatsu, \& Ramirez, 2010).

- Absence of standardization among organisations (Drabek \& McEntire, 2003).

- Donor independence (Kovács \& Spens, 2009).

- Appearance of self-initiated participants (Drabek \& McEntire, 2003).

- Human and material resources from multiple participants and jurisdictions (Auf der Heide, 1989).

As a result, Altay and Green (2006) proposed the development of studies to facilitate coordination among agencies in disaster management. That was supported by Galindo and Batta (2013) calling for researchers to incorporate coordination initiatives into their models.

Recently, Özdamar and Ertem (2015) provided a review of Information Systems solutions to aid coordination such as GIS. Operational Research can also provide support to enable coordination. Resource allocation models allow pooling resources from different participants, which can prove effective for disaster operations (Balcik et al., 2010).

The focus of this research is to enhance coordination through of the use of resources. The variation of labour and material resources makes resource management among different organisations an essential element to satisfy the needs of disaster victims. Managing those resources is challenging because of jurisdictional boundaries, shortages or excess of resources, complications sharing information, and mixed allocation of tasks and resources among different organisations (Auf der Heide, 1989). A system capable of providing a setting for guiding and directing participant organisations in order to satisfy the needs of disaster victims could mitigate the impact of those problems. 
Relief items are only one kind of resource required for disaster management. It is important to study the allocation of people, vehicles and equipment as well. There are papers concentrating on the allocation of teams or units (Maya Duque, Dolinskaya, \& Sörensen, 2016; Wex, Schryen, Feuerriegel, \& Neumann, 2014), volunteers (Falasca \& Zobel, 2012), rescue activities (Barbarosoğlu, Özdamar, \& Çevik, 2002), and allocation and delivery of equipment (Chen, Peña-Mora, \& Ouyang, 2011).

Related to the topics studied in this work, Arora, Raghu, and Vinze (2010) focused on the allocation of medical aid for emergencies considering the coordination between regions, whereas Adivar and Mert (2010) aimed to coordinate international relief items using fuzzy logic to provide a collectiondistribution plan. Altay (2013) developed a model to allocate response personnel, facilities, supplies and equipment with two alternative objective functions; to minimise deployment time or minimise maximum response time. The model, in addition, minimises simultaneously total deployment time and the total capability deficit for shortages. Edrissi, Poorzahedy, Nassiri, and Nourinejad (2013) developed a system for strengthening structures, retrofitting transportation links and equipping emergency response centres by coordinating different organisations nearby and maximising survival rates. Chang et al. (2007) used vector GIS to determine demand through flooding potential maps. They proposed a stochastic model to determine clusters of demand by minimising the expected shipping distance, and a two-stage stochastic model minimising total cost to determine rescue bases in the first stage, and amount of rescue equipment and transportation plans in the second stage.

Based on the literature analysis, it can be stated that emergency logistics articles often neglect to consider multi-organisational settings. That creates a significant complication for the application of these models in the Mexican disaster management framework. Even among resource allocation models an important consideration is missing. The natural reaction of national governments is to send as many agencies and resources as possible to affected communities. Having more participants involved, however, is no guarantee to get better operations. Excess in material resources can create congestion, bottlenecks and the need to classify useful from useless resources. Similarly, more employees require more resources, increase safety issues (Abounacer et al., 2014), and there is the potential for underused capacity, idle resources and congestion (Wenger, Quarantelli, \& Dynes, 1986). A key challenge for the deployment of resources is to determine how many organisations to involve, and perhaps more importantly, which ones are needed.

Currently there are no papers optimising the number of actors involved or disaggregating resources from different agencies for cooperative facilities and operations, which in turn can derive a better use of pooled resources. The system introduced in the next section aims to tackle the gaps identified using the collaboration setting currently in place in Mexico to support operations in the field. 


\section{SYSTEM DESIGN}

The system proposed uses a combination of GIS and optimisation. The GIS is used to analyse potential flood situations in order to provide information about the impact of the disaster in the region. The model can handle several participants to identify the optimal combination of organisations and resources necessary to perform logistics activities and satisfy the requirements of the victims.

\subsection{Geographical Information Systems}

Most articles in the literature are using GIS for data pre-processing, network analysis and data display, although there are several potential contributions of GIS to different disaster management phases (Özdamar \& Ertem, 2015). Unlike earthquakes, in which the damage depends on the epicenter, many floods can be analysed considering the vulnerability of the area and the level of rainfall (PedrozoAcuña et al., 2014). Based on that, flood maps can be developed, making GIS relevant for flood management.

For this research, risk and potential damage are incorporated using GIS. Involving geographical factors in the analysis allows to provide more accurate information for the model, increase the level of reliability of the facilities selected, identify demand sources better, recognise the vulnerability per area, and incorporate suitable roads.

Building upon Rodríguez-Espíndola and Gaytán (2015), the approach undertaken here includes vector GIS to locate suitable facilities and perform network analysis; whereas raster GIS is used to consider different scenarios and discard facilities prone to flooding. The three stages are shown on Figure 1.

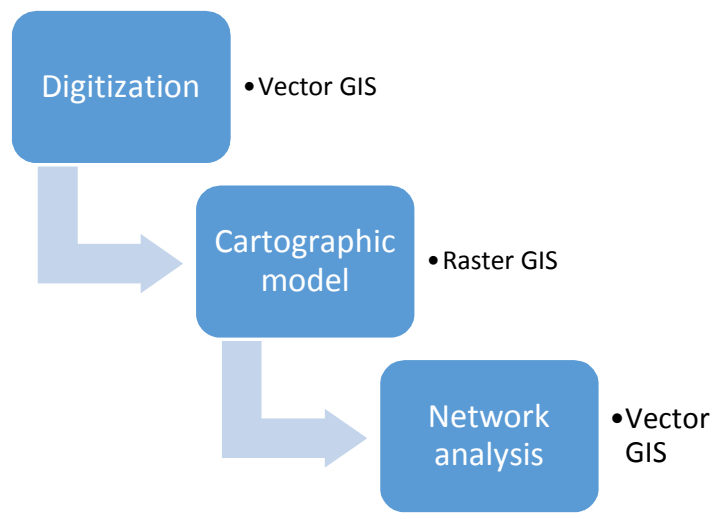

Figure 1. Geographical procedure

Digitization can be performed using vector software to obtain the layers required. The user can obtain the road network and demand areas from authorities, or draw them using satellite pictures. The level of detail of the maps can affect the analysis, thus it is expected to be revised prior to their use to ensure accuracy. Next, each one of the emergency facilities can be identified using coordinates or addresses. Additionally, assuming one assembly point for evacuation, a central point in each area should be identified so as to calculate distances.

Cartographic modelling uses map algebra to integrate maps of individual characteristics to treat them 
as variables that can be combined or transformed through specific functions (Tomlin, 1991). Employing the steps provided by Martin (1993) and map algebra as suggested by RodríguezEspíndola and Gaytán (2015), a cartographic model can be implemented in raster software. The parameter used to vary scenarios relies on the expected water height, because of weather conditions or a particular phenomenon. The water height used ought to be based on the peak of the event for the solution to provide reliable facilities over the entire situation.

For this analysis, a digital elevation model (image that contains the elevation of each point of the studied area) is needed and it should be carefully selected. The accuracy of the map can be supplied by the provider and it should be tested beforehand to ensure the quality of the solution.

The macro model used to represent the cartographic model can be seen in Figure 2. The overall steps are to introduce the altitude of the area to create a base situation and then add a value for the height of the flood. Then, the "dry" and "flooded" areas are reclassified with a value of 1 and 0 , respectively. The overlay module is used to discard facilities prone to flooding and assess the damage to demand areas. The results are layers with available shelters, distribution centres and the extent of damage of each demand area for each scenario.

After the flood image is obtained, it can be overlapped with the road network to identify roads affected. As the GIS procedure requires only the layers described and the expected conditions of the flood, the analysis can be repeated under different instances. It can be employed far in advance for planning purposes and to test the operational boundaries of the current policy, or close to the disaster to prepare logistics decisions to cope with the situation. A significant advantage of the GIS is that it considers the real features of the region. The information obtained from the assessment of the flood is considering the possibility of links in a road being flooded and the existence of connecting roads, taking full advantage of the road network. The user can define worse conditions than expected to incorporate a degree of uncertainty in the situation. The purpose is to ensure the suitability of the facilities selected and having a reliable supply of resources.

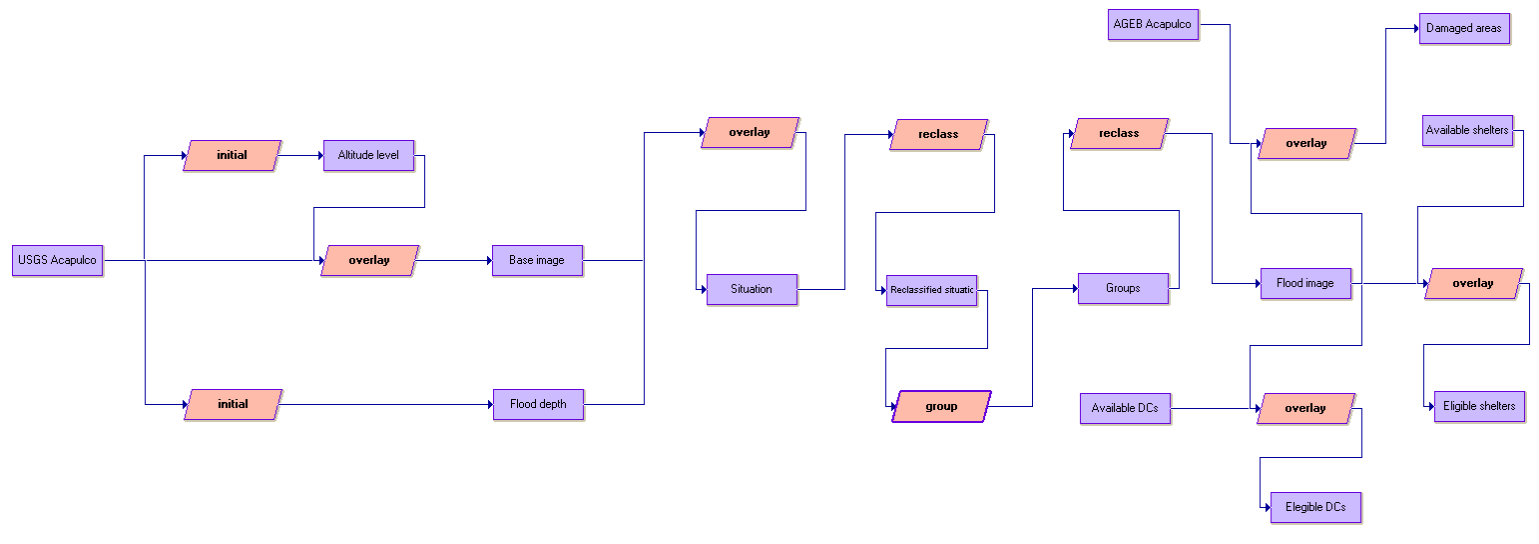

Figure 2. Cartographic model 
Having that information, network analysis can be performed using vector GIS. Considering only surviving roads and facilities, the shortest distance between every pair of nodes can be determined. The shortest road path between facilities can be used for land transportation, whereas Euclidian distances can be obtained for other transportation modes. The results from the geographical procedure are a list of candidate facilities, a matrix of connectivity between facilities along with the distance between them, and a percentage of damage caused by the flood to demand areas.

\subsection{Preparedness optimisation model}

This paper introduces a quantitative model based research approach (Bertrand \& Fransoo, 2002). Based on the context of the problem, the mathematical model developed is presented in this section. The use of one performance measure can be inadequate for disaster management (Beamon \& Balcik, 2008), even with the development of 'social cost' functions (Huang, Jiang, Yuan, \& Zhao, 2015; Sheu, 2014). According to Savas (1978), there are three key performance indicators for public services: efficiency, effectiveness and equity. Cost was selected as a resource-based measure to achieve efficiency (See Beamon \& Balcik, 2008). The decision was based on a meeting with Mexican military authorities [National Defence Secretariat (SEDENA), personal communication, March 11, 2010] in which the relevance of cost for the potential selection of a disaster management policy was specified. Also, cost is the most common resource-based performance measure used in the literature.

The second performance measure incorporated in the model, namely fulfillment rate, is adopting the point of view of the victims and seeking effectiveness. Fulfilment rate is based on products and services provided at shelters and it is measured in three dimensions: the fulfilment of relief items, the presence of healthcare personnel for injuries and diseases, and the availability of shelter personnel for security, cooking, social activities, among others.

Equity is included in the model using the performance measure related to fill rate. The formulation is using a min - max objective function, which can be classified as an equality-based method (Huang et al., 2015). The purpose is to minimise the maximum level of unfulfillment among all shelters, thereby balancing the fill rate across them.

The core of the model is to decide the best policy in terms of the resources available. The need to balance efficiency and effectiveness is shared by the organisations involved, complementing each other to achieve the higher benefit for the system. Several experiences show that having too much sometimes can be almost as harmful as not having enough (Auf der Heide, 1989). This model is the first of its kind capable of deciding which organisations are required in the field to avoid shortages or convergence. It is capable of providing tailored operations according to the circumstances to use available resources in an efficient way whilst providing adequate support to disaster victims. 
Supported by the flood analysis performed using the GIS, the model is able to determine the location of emergency facilities, establish the allocation of resources (material and human) to use for each activity, decide which organisations should be involved according to the event, and perform the allocation of distribution for the initial response phase right after disaster. These decisions are represented on Figure 3.

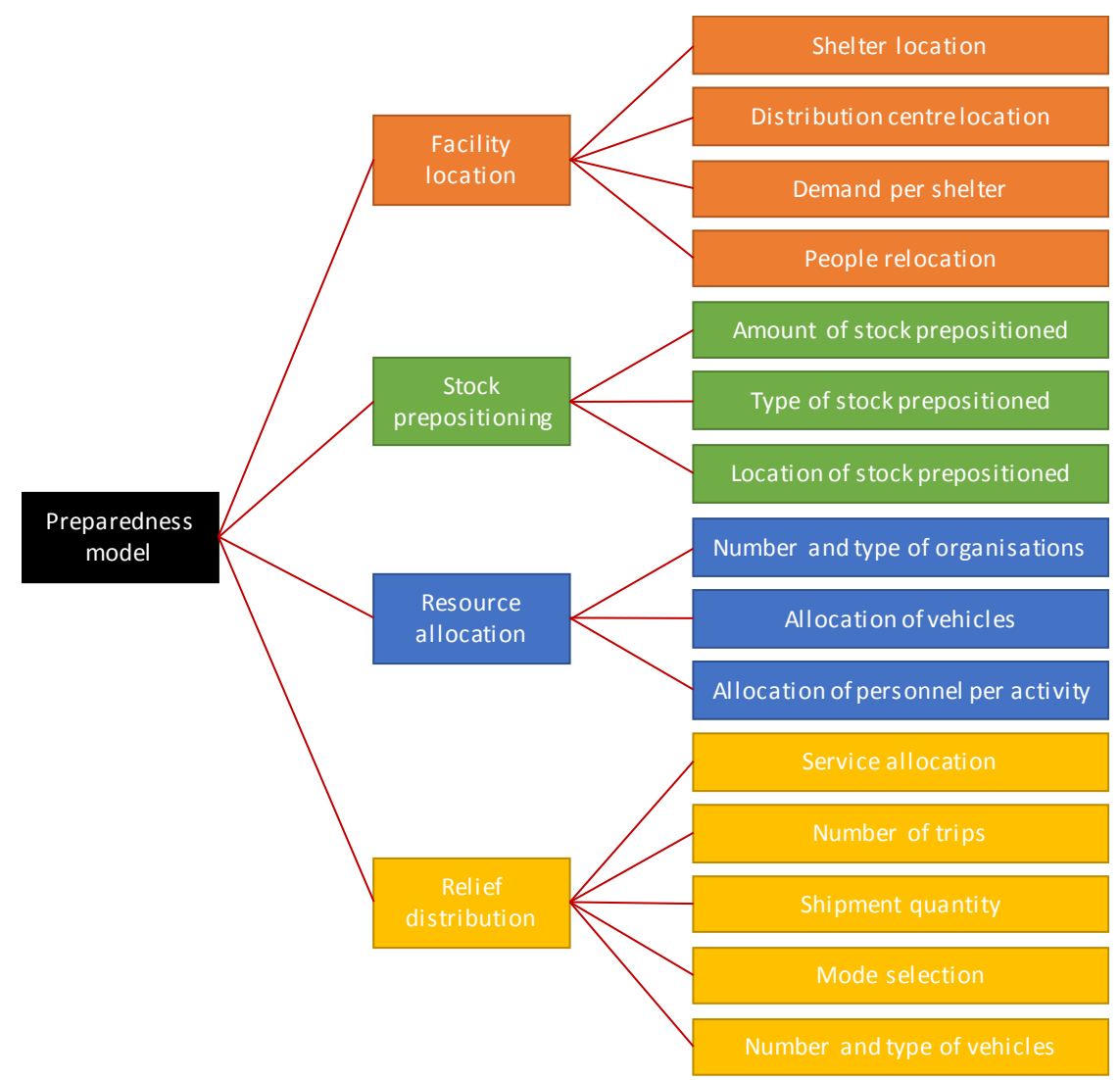

Figure 3. Set of decisions determined by the preparedness optimisation model

\subsubsection{Model assumptions and context}

A clear set of assumptions underpinning the model ought to be established in order to limit its scope and have a manageable set of variables. The main assumptions are as follows:

- There is one centralised decision-maker authority with control over the preparedness plan and jurisdiction to coordinate the other organisations involved.

- The organisations considered are available for immediate deployment.

- Information about the available resources from eligible organisations is available and updated.

- Once an organisation is activated all of its resources become available, i.e. there is no partial activation of organisations.

- Transportation costs are only dependent on the fuel spent to perform the delivery. Vehicles are pre-owned by the organisations involved, leaving depreciation aside.

- People are informed prior to an evacuation their allocated shelter and pre-disaster evacuation procedures are in place. 
- The number of facilities to set-up is based on the resources available along with the features of the disaster, not a pre-defined number determined by authorities.

- Both objectives are relevant for the decision maker with no clear dominance among them. The decision-making authority should work as a coordinator able to guide, instruct and oversee the actions of the organisations during the emergency. This decision-maker can be a leading agency, a council from other organisations, or a government. Despite not owning the resources, it would have the information and capability to guide the operational activities. The reason for the use of a decisionmaker in such fashion is because it is the approach chosen by some organisations including the Mexican government, with the purpose of having a participant looking at the whole situation. That approach makes it possible to identify a way to coordinate the associated organisations in order to satisfy the needs generated by the disaster.

\subsubsection{Notation and definitions}

The parameters of this model were classified as generic, case-specific and disaster-specific. Casespecific parameters depend on the area of study and disaster policies, disaster-specific parameters rely on the particular situation and the magnitude of the event, and generic parameters are not linked to either one. The variables were classified as intermediate variables and decision variables. The intermediate variables include elements associated with the calculations performed to obtain the values of the decision variables, which are the relevant factors affecting policy. The sets, parameters and variables included in the model are presented as follows:

$$
\begin{array}{ll}
\text { Sets } & \\
\mathrm{I} & \text { Candidate distribution centres, } I=\{1,2,3, \ldots,|\mathrm{I}|) \\
\mathrm{J} & \text { Candidate shelters, } J=\{1,2,3, \ldots,|J|) \\
\mathrm{K} & \text { Demand areas, } K=\{1,2,3, \ldots,|K|) \\
\mathrm{M} & \text { Transportation modes, } M=\{1,2,3, \ldots,|M|) \\
\mathrm{N} & \text { Products, } N=\{1,2,3, \ldots,|N|) \\
\mathrm{O} & \text { Organisations, } O=\{1,2,3, \ldots,|\mathrm{O}|)
\end{array}
$$

Generic parameters

$$
\begin{array}{ll}
\text { VOL }_{\mathrm{n}} & \text { Volume per product } n\left(\frac{\mathrm{m}^{3}}{\text { product }}\right), n \in|N| \\
\mathrm{WEI}_{\mathrm{n}} & \text { Weight per product } n\left(\frac{\mathrm{kg}}{\text { product }}\right), n \in|N| \\
\mathrm{F}_{\mathrm{m}} & \text { Weight vehicle capacity of mode } m\left(\frac{\mathrm{kg}}{\text { trip }}\right), m \in|M| \\
\mathrm{G}_{\mathrm{n}} & \text { Conversion factor for each product } n\left(\frac{\text { people }}{\text { product }}\right), n \in|N|
\end{array}
$$

\section{Case-specific parameters}

RPC Space covered per distribution centre employee $\left(\frac{m^{3}}{\text { employee }}\right)$ 
$\mathrm{RPH} \quad$ Number of people covered per healthcare team $\left(\frac{\text { people }}{\text { team }}\right)$

APDC Percentage of personnel required for partial opening of DCs, $0 \leq A P D C \leq 1$

$\mathrm{CA}_{\mathrm{i}} \quad$ Opening cost per distribution centre $i(\$), i \in|I|$

$\mathrm{CC}_{\mathrm{j}} \quad$ Opening cost of shelter $j(\$), j \in|J|$

$\mathrm{CP}_{\mathrm{n}} \quad$ Procurement cost per product $n\left(\frac{\$}{\text { product }}\right), n \in|N|$

$\mathrm{C}_{\mathrm{j}} \quad$ Capacity of shelter $j$ (people), $j \in|J|$

$\mathrm{A}_{\mathrm{i}} \quad$ Storage capacity of distribution centre $i\left(\mathrm{~m}^{3}\right), i \in|I|$

$\mathrm{AVD}_{\mathrm{m}} \quad$ Available number of trips per day per mode $m\left(\frac{\text { trips }}{\text { vehicle }}\right), m \in|M|$

$\mathrm{RDP}_{\mathrm{m}} \quad$ Distribution personnel required per mode $m\left(\frac{\text { employees }}{\text { vehicle }}\right), m \in|M|$

WAGE $_{\mathrm{o}} \quad$ Wages paid for the activation of organisation $o(\$), o \in|O|$

$\mathrm{PAC}_{\mathrm{o}} \quad$ Usable personnel from organisation $o$ for DC operation (employee), $o \in|O|$

$\mathrm{PAS}_{\mathrm{O}} \quad$ Usable personnel from organisation $o$ for shelter care (employee), $o \in|O|$

$\mathrm{PAH}_{\mathrm{o}} \quad$ Available teams from organisation $o$ for healthcare (team), $o \in|O|$

$\mathrm{PAD}_{\mathrm{o}} \quad$ Available personnel from organisation $o$ for distribution (employee), $o \in|O|$

$\mathrm{TP}_{\mathrm{o}} \quad$ Total operative personnel available per organisation $o$ (employee), $o \in|O|$

$\mathrm{IP}_{\mathrm{no}} \quad$ Product inventory of type $n$ from organisation $o$ (products), $n \in|N|, \mathrm{o} \in|O|$

$\mathrm{TV}_{\mathrm{mo}} \quad$ Vehicles available of type $m$ per organisation $o$ (vehicles), $m \in|M|, o \in|O|$

Disaster-specific parameters

TIER $_{\mathrm{n}} \quad$ Priority of product $n, n \in|N|$

$\mathrm{EP}_{\mathrm{k}} \quad$ Population to be sheltered per demand area $k$ (people), $k \in|K|$

$\mathrm{CS}_{\mathrm{ijm}} \quad$ Cost of delivering relief from distribution centre $i$ to shelter $j$ by mode $m\left(\frac{\$}{\text { trip }}\right), i \in$ $|I|, j \in|J|, m \in|M|$

$\mathrm{CON}_{\mathrm{ijm}} \quad$ Connectivity between distribution centre $i$ and shelter $j$ by mode $m, \operatorname{con}_{i j m} \in[0,1]$, $i \in|I|, j \in|J|, m \in|M|$

$\mathrm{SA}_{\mathrm{ijm}} \quad$ Service availability for relief distribution from distribution centre $i$ to shelter $j$ by mode $m$ based on coverage, $S A_{i j m} \in[0,1], i \in|I|, j \in|J|, m \in|M|$

$\mathrm{SC}_{\mathrm{kj}} \quad$ Coverage of demand area $k$ by shelter $j, S C_{k j} \in[0,1], j \in|J|, k \in|K|$

Intermediate variables

TRAV $_{\mathrm{ijm}} \quad$ Number of trips deployed from DC $i$ to shelter $j$ by mode $m$ (trips)

$\mathrm{IPD}_{\mathrm{jn}} \quad$ Number of products of type $n$ required at shelter $j$ (products)

$\operatorname{DSAT}_{\mathrm{jn}} \quad$ Demand of product $n$ not fulfilled on shelter $j$ (products)

DISP $_{\mathrm{kj}} \quad$ Number of people to be allocated from demand zone $k$ to shelter $j$ (people) 


$\begin{array}{ll}\mathrm{NVH}_{\mathrm{j}} & \text { Expected number of people without healthcare at shelter } j \text { (people) } \\ \mathrm{PVH}_{\mathrm{j}} & \text { Expected surplus of people covered for healthcare at shelter } j \text { (people) } \\ \mathrm{NVS}_{\mathrm{j}} & \text { Expected number of people without shelter attention at shelter } j \text { (people) } \\ \mathrm{PVS}_{\mathrm{j}} & \text { Expected surplus of people covered for shelter attention at shelter } j \text { (people) } \\ \mathrm{MAD}_{\mathrm{j}} & \text { Maximum number of people with relief shortages at shelter } j \text { (people) }\end{array}$

Decision variables

$\mathrm{X}_{\mathrm{i}} \quad$ Whether to open distribution centre $i$ or not

$\mathrm{Y}_{\mathrm{j}} \quad$ Whether to open shelter $j$ or not

$\mathrm{W}_{\mathrm{o}} \quad$ Whether to activate organisation $o$ or not

$\mathrm{PRE}_{\text {ino }} \quad$ Quantity of stock of product $n$ from agency $o$ to preposition on DC $i$ (products)

SHIP $_{\mathrm{ijmn}} \quad$ Amount of relief of type $n$ to send from DC $i$ to shelter $j$ by mode $m$ (products)

$\mathrm{PC}_{\mathrm{io}} \quad$ Number of personnel from organisation $o$ to allocate to DC $i$ (employee)

$\mathrm{PS}_{\mathrm{jo}} \quad$ Number of personnel from organisation $o$ to allocate to shelter $j$ (employee)

$\mathrm{PH}_{\mathrm{jo}} \quad$ Number of teams from organisation $o$ to allocate to shelter $j$ for healthcare (team)

PDimo Number of personnel from organisation $o$ to allocate for distribution to DC $i$ (employee)

$\mathrm{AV}_{\text {imo }} \quad$ Number of type $m$ vehicles from organisation $o$ to allocate at DC $i$ (vehicles)

$\mathrm{D}_{\mathrm{j}} \quad$ Number of people to be allocated to shelter $j$ (people)

UFR Maximum unfulfilled demand (people)

Cost Total cost incurred by the policy $(\$)$

This model can be used to analyse a set of different scenarios depending on the circumstances of the flood. Disaster -specific parameters are relevant for sensitivity analysis, and these are affected by the geographical procedure. Specifically, the priority of the product $\left(\mathrm{TIER}_{\mathrm{n}}\right)$ and the number of people to be sheltered $\left(\mathrm{EP}_{\mathrm{k}}\right)$ can be used to explore different scenarios and develop managerial insights.

Discussing the personnel required per activity, these parameters can be provided by the organisations based on current practice and guidelines. For the case of Mexico, authorities have values of the number of staff needed per activity to provide support to a determined number of people. Similarly, Mexican authorities have standard units for distribution which can support a number of people for a number of days. For instance, food pantries are designed to provide support for 4 people for 4 days. That information is used by the model to determine the requirements at each facility based on the expected number of people to evacuate per area $\left(\mathrm{EP}_{\mathrm{k}}\right)$.

The expected number of people to evacuate represents a very important parameter for the system. The GIS analysis of different scenarios can provide insights about the potential damage of the area, which combined with demographic information can provide information about vulnerable population under different instances. The advantage of the use of the GIS is because introducing geographical conditions in the process supports the identification of potential sources of demand. After thorough 
analysis using the GIS, the results should be coupled with research in evacuation decisions, historical information, and demand estimation algorithms to determine the number of expected people to serve during the emergency.

\subsubsection{Model formulation}

The model designed contains only deterministic variables. Liberatore, Pizarro, de Blas, Ortuño, and Vitoriano (2013) and Alem, Clark, and Moreno (2016) identified the main sources of uncertainty on emergency logistics: demand, demand location, affected areas, supply, and transportation network.

For the case of this research, uncertainty in supply is neglected because of the preparedness nature of the model and the prepositioning strategy adopted, not to mention the 'limitless' availability according to Mexican authorities [National Defence Secretariat (SEDENA), personal communication, March 11, 2010]. Demand estimation is outside our scope and it is expected to be determined employing forecasting methods (Sheu, 2014), applying GIS for mapping and assessment (e.g. Kourgialas \& Karatzas, 2011), historical data, and/or using research of evacuation decision-making (Lim, Lim Jr, \& Piantanakulchai, 2013; Lindell, Kang, \& Prater, 2011). The transportation network, demand location and affected areas are evaluated using GIS, and scenario analysis can also be employed to use only safe roads even under the hardest conditions.

In the model, the allocation of people to safe places allows authorities to have an estimation of the demand to be expected at each facility based on the sources of demand determined by the GIS. As part of the preparedness plan, the estimation is expected to be informed to the population and used by authorities to guide evacuation.

An important aspect of the design of the model is the multi-organisational perspective. By including the agencies as a set, data from each individual organisation can be introduced to find the best combination, deciding whether the activation of an organisation is justified or not, and deciding how to use the resources available (people, vehicles, relief items). In this approach, although there is a decision-maker overseeing operations, it only provides guidance and instructions to articulate individual organisations carrying out their own activities. For instance, if there are governmental agencies for food security, medicines, social security and family services, the model can instruct each one of them where to allocate their individual efforts to build upon the larger task to satisfy demand. Hence, resource allocation and the participation of individual organisations are incorporated in the model, with clear directives and taking advantage of the resources from each participant. Other models could not provide that guidance based on the overlapping resources of each agency.

The approach proposed here includes only necessary organisations (preventing overcrowding) and enables collaboration through the allocation of tasks to each actor. Existing models considering one participant encourage activating every agency available (because of the combination of resources), leaving task and resource allocation to other decision mechanisms. The formulation presented here 
allows more flexibility for planning and preparedness as it activates organisations depending on the circumstances. The model is structured as follows:

$\operatorname{Min} \operatorname{COST}=\sum_{i} C A_{i} * X_{i}+\sum_{j} C C_{j} * Y_{j}+\sum_{o} W A G E_{o} * W_{o}+\sum_{i} \sum_{n} \sum_{o} C P_{n} * P R E_{\text {ino }}+$ $\sum_{i} \sum_{j} \sum_{m} C S_{i j m} * T R A V_{i j m}$

$\operatorname{Min} U F R=\max _{j \in J}\left(\frac{\left(M A D_{j}+N V H_{j}+N V S_{j}\right)}{3 * C_{j}}\right)$

s.t

$$
\begin{aligned}
& D_{j}=\sum_{k} D I S P_{k j} \\
& E P_{k}=\sum_{j} D I S P_{k j} * S C_{k j} \\
& I P D_{j n} * G_{n} \geq D_{j} \\
& D S A T_{j n}=I P D_{j n}-\sum_{i} \sum_{m} S H I P_{i j m n} \\
& M A D_{j} \geq \frac{\sum_{n} D S A T_{j n} * G_{n} * T I E R_{n}}{\sum_{n} T I E R_{n}} \quad \forall j \\
& \mathrm{D}_{\mathrm{j}} \leq C_{j} * Y_{j} \\
& \sum_{n} \sum_{o} P R E_{\text {ino }} * V O L_{n} \leq A_{i} * X_{i} \\
& \sum_{i} P R E_{\text {ino }} \leq I P_{n o} * W_{o} \\
& \sum_{j} \sum_{m} S H I P_{i j m n} \leq \sum_{o} P R E_{\text {ino }} \\
& A P D C * A_{i} * X_{i} \leq \sum_{o}\left(P C_{i o} * R P C\right) \\
& D_{j}=\sum_{o}\left(P H_{j o} * R P H\right)+N V H_{j}-P V H_{j} \\
& D_{j}=\sum_{o}\left(P S_{j o} * R P S\right)+N V S_{j}-P V S_{j} \\
& \sum_{i} P C_{i o} \leq P A C_{o} * W_{O} \\
& \sum_{j} P S_{j o} \leq P A S_{o} * W_{o} \\
& \sum_{j} P H_{j o} \leq P A H_{o} * W_{o} \\
& \sum_{i} \sum_{m} P D_{i m o} \leq P A D_{o} * W_{o}
\end{aligned}
$$




$$
\begin{array}{cc}
\sum_{i} P C_{i o}+\sum_{j} P S_{j o}+\sum_{j} P H_{j o}+\sum_{i} \sum_{m} P D_{i m o} \leq T P_{o} * W_{o} & \forall o \\
\sum_{n} S H I P_{i j m n} * W E I_{n} \leq F_{m} * T R A V_{i j m} * C O N_{i j m} * S A_{i j m} & \forall i, j, m \\
\sum_{j} T R A V_{i j m} \leq \sum_{o} A V_{i m o} * A V D_{m} & \forall i, m \\
\sum_{i} A V_{i m o} \leq T V_{m o} * W_{o} & P D_{i m o} \\
R D P_{m} & \\
\mathrm{X}_{\mathrm{i}}, \mathrm{Y}_{\mathrm{j}}, \mathrm{W}_{\mathrm{o}} \in\{0,1\} & \\
\mathrm{PRE}_{\mathrm{ino}}, \mathrm{TRAV}_{\mathrm{ijm}}, \mathrm{D}_{\mathrm{j}}, \mathrm{DISP}_{\mathrm{kj}}, \mathrm{IPD}_{\mathrm{jn}}, \mathrm{DSAT}_{\mathrm{jn}}, \mathrm{SHIP}_{\mathrm{ijmn}}, \mathrm{PH}_{\mathrm{jo}}, \mathrm{PC}_{\mathrm{io}}, \mathrm{NVH}_{\mathrm{j}}, \mathrm{NVS}_{\mathrm{j}}, \\
\mathrm{PVH}_{\mathrm{j}}, \mathrm{PVS}_{\mathrm{j}}, \mathrm{MAD}_{\mathrm{j}}, \mathrm{PS}_{\mathrm{jo}}, \mathrm{PD}_{\mathrm{imo}}, \mathrm{AV}_{\mathrm{imo}} \in \mathrm{Z} \geq 0 &
\end{array}
$$

Objective function (1) is used to minimise costs associated with the location of facilities, personnel, procurement and transportation, whereas objective function (2) minimises the maximum unfulfillment of products and services across all the shelters to serve as a measure of equity. Constraint (3) determines demand of people at each shelter and expression (4) ensures that every evacuee reaches a shelter. Equation (5) determines demand per product at each shelter, whereas expression (6) establishes unfulfilled demand and constraint (7) determines the maximum demand unsatisfied across the different products per shelter. Expressions (8) and (9) deal with people capacity of shelters and storage capacity of distribution centres, respectively. Constraint (10) restricts the maximum amount of relief items to preposition available across all agencies and equation (11) ensures that only relief items available are shipped. Constraint (12) allows the partial opening of distribution centres and determines the number of people required to operate these facilities, whereas expressions (13) and (14) determine the number of personnel allocated and shortages of service for healthcare and shelter attention, respectively. Equations (15), (16), (17) and (18) establish the maximum number of personnel available across all agencies for distribution centres, shelters, healthcare and distribution respectively; whereas constraint (19) ensures that the maximum number of operative people per organisation activated is not bridged including the term for healthcare teams if and only if one member is available for operative support such as the distribution of medicines. Expression (20) determines the number of trips from each DC to each shelter for distribution, constraint (21) establishes the number of vehicles required, equation (22) the number of employees needed, and expression (23) ensures the maximum number of vehicles available is not exceeded. Finally, the declaration of binary and integer variables is presented. 


\subsubsection{Model solution}

The use of more than one performance measure delivers a set of efficient solutions. To obtain that set, an a posteriori approach can be used. In this approach, the Pareto frontier is generated and afterwards the decision-maker choses the preferred solution among the different possibilities (Miettinen, 2008). Scalarization techniques are a traditional approach to solving these kind of problems by replacing a vector problem into a family of scalar optimisation problems. Among them, the weighted-sum method and the $\varepsilon$-constraint method were selected for this research. The former is selected because of simplicity and accuracy, whereas the latter is used to tackle the limitation of the weighted-sum method to obtain solutions for non-convex problems.

In the overall solution procedure, the Pareto frontier is generated using both methods. The models can be programmed on commercial software selecting a MIP solver. Next, the Pareto frontier is taken to the decision-maker, in order to explain to him/her the concept of trade-off and search for the solution that is closer to his/her preferences. Once the decision-maker finds a suitable point, information about the policy can be displayed for assessment, and the possibility to move to another solution on the frontier can be offered until the decision-maker is satisfied.

\section{APPLICATION OF THE SYSTEM TO THE FLOOD OF ACAPULCO, MÉXICO}

\subsection{Region of study}

Acapulco is a city located in the State of Guerrero, Mexico. It is in the Pacific coast of the country next to the sea but surrounded on the other side by mountains, as shown in Figure 4. The city has a strong focus on tourism, as shown by the 4,890,456 tourists that visited the region just in 2010 (INEGI, 2010a), to make it one of the most important touristic ports in Mexico (García et al., 2015).

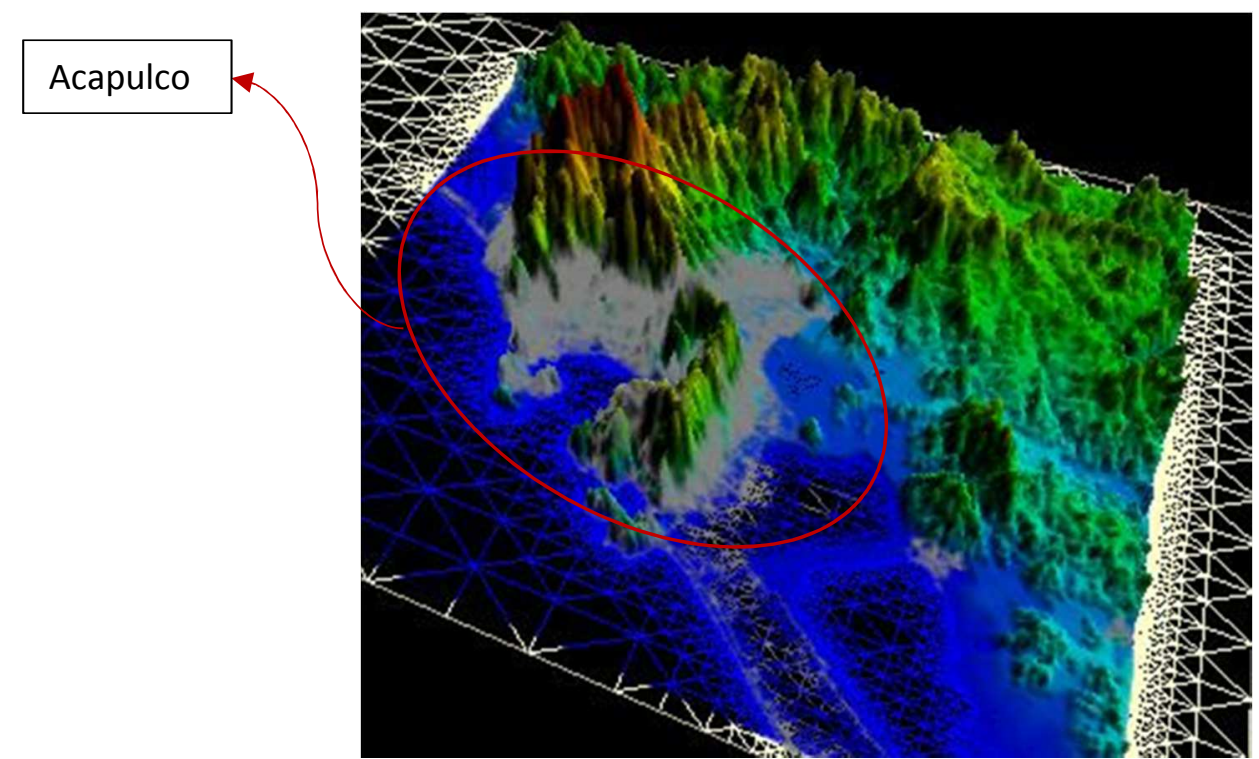

Source: USGS (2010) and INEGI (2010b)

Figure 4. Image of Acapulco, Guerrero 
Using the real situation experienced in Acapulco, empirical quantitative research (See Bertrand \& Fransoo, 2002) is used looking to show the performance of the model under real circumstances and provide insights for the improvement of the current decision-making mechanisms.

A total of three scenarios were introduced. The reported height of water reached by the flood of 2013 (1.5 meters) was used as the main scenario. However, bearing in mind the importance of observing the behaviour of the system under different conditions, scenarios of a water depth of 0.5 meters and 2.5 meters were also analysed as being considered relevant thresholds because of their impact on people's property and safety.

\subsection{Data gathering}

From the government organisations involved in the management of operations in hydrological disasters in the country, the ones identified to supply human and material resources in the field were approached. The purpose was to gather information about their involvement in the flood of 2013, their resources deployed and the outcome of their activities. Twelve organisations acknowledged their participation in the event and declared to have information; four at the State level and eight at the National level. A total of 205 FOI requests were filed to these organisations to obtain the information. Among them, the National Centre for Disaster Prevention (CENAPRED) and the Ministry of Exterior were enquired only about reports of the situation and international aid.

Information from ten government agencies involved in operational activities during the disaster was successfully gathered. The replies included information across health services (Health Ministry (SMEXICO), Health Secretariat of the State (SGUERRERO) and Mexican Institute of Social Security (IMSS)), food services (DICONSA and SEDESOL), family services (DIF), military (SEDENA and SEMAR) and civil protection (SSPPC). The information requested included activities related to facility management, the number of people sheltered and cared for, the number of relief items available before the emergency and subsequently deployed, the type and number of vehicles used, the number of employees available and their allocation to different activities, and operational costs.

For the geographical analysis the information was obtained from the National Institute of Statistics and Geography (INEGI) and the United States Geological Survey (USGS). The former provided the road network, and urban design, whereas the latter provided a DEM of the area chosen based on accuracy. The list of shelters included 103 facilities from the shelter catalogue of 2013 in the area (SSPPC, 2013), whereas information from DIF, SSPPC, SEDENA and DICONSA was used to identify 14 available DCs.

\subsection{Geographical analysis}

TransCAD® was selected to perform the digitization of the emergency facilities. Each facility was located and georeferenced in the software using information from the shelter list. The cartographic model was implemented in a macro in IDRISI ${ }^{\circledR}$ to obtain flood maps under the scenarios proposed. 
Having the representation of the flood, map algebra was used to combine the flood map with the layers of facilities, roads and demand areas. The result was the identification of damage on demand areas, the availability of roads, and the suitability of potential shelters and distribution centres.

In terms of facilities, the analysis yielded 101 shelters available for the scenario of 0.5 meters, and 99 shelters remaining for the floods of 1.5 and 2.5 meters. On the other hand, a total of 12 candidate distribution centres survived the conditions for the floods of 0.5 meters and 1.5 meters, whereas the situation with a height of water of 2.5 meters delivered 10 candidate facilities. The location of the surviving shelters (small) and distribution centres (medium) for the real conditions of the emergency can be seen in Figure 5. The flood of 0.5 meters affected nearly $17.6 \%$ of the total area, whereas the flood of 1.5 meters and 2.5 meters damaged around $19.9 \%$ and $22 \%$ of the region, respectively.

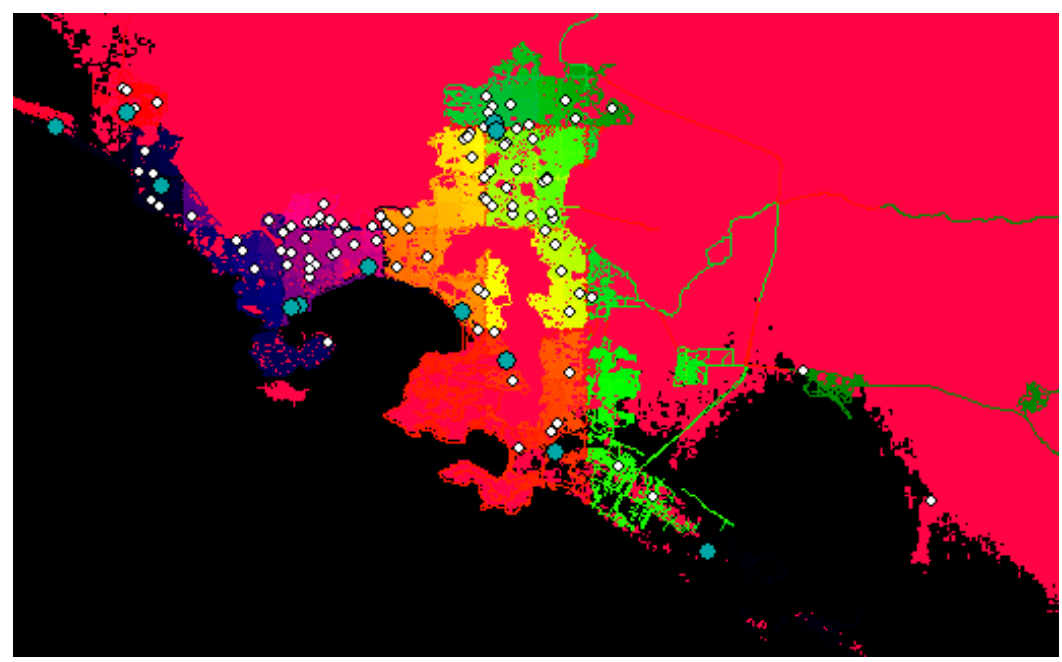

Figure 5. Surviving facilities under the conditions of the flood in Acapulco in 2013

The flood map along with the road network was used to obtain the connectivity matrix using of the Floyd-Warshall algorithm. For each combination of facilities a value of 1 was input as long as there was at least one road available between the facilities and 0 otherwise. For the latter, boat transportation was assumed to be possible. Afterwards, TransCAD® was used to perform network analysis in the region in order to identify distances and coverage between facilities.

\subsection{Application of the preparedness optimisation model}

The results from the GIS were combined with information gathered from the government agencies to create databases included as parameters in the preparedness model. The model is able to support data from different organisations without aggregating it, allowing to identify the best solutions by balancing resources available and logistics requirements.

The data used in this research was obtained directly from the organisations sampled. Generic parameters were obtained from Mexican regulations. Case-specific parameters were provided directly form the organisations involved. That information is based on the inventory of resources from each organisation, their internal operational guidelines and the details of facilities used by civil protection 
authorities. Most disaster-specific parameters were obtained from the result of the flood analysis using the GIS, with the exception of the expected number of people to shelter. For the purposes of this research and for comparability, that value was obtained from the records of the number of people sheltered by SGUERRERO, SSPPC, SEDENA and IMSS.

The model was coded into GAMS 23.5.1® using Cplex® as solver for MIP. In order to obtain the Pareto frontier of the set of efficient solutions, the weighted-sum method and the $\varepsilon$-constraint method were applied. The weighted sum-method creates a weighted combination of both performance measures. This method was coded for 200 combinations of weights among the objectives ranging from 0 to 1 , which were normalised using the ideal values of minimising each individual objective.

For the $\varepsilon$-constraint method the cost function was used as a constraint for 200 values, varying from minimum to maximum cost, to minimise the level of unfulfillment. Each iteration had a time limit of 450 seconds. After collating the results from both methods and filtering efficient solutions, Figure 6 depicts 39,62 and 86 non-dominated points for floods of $0.5,1.5$ and 2.5 meters, respectively.

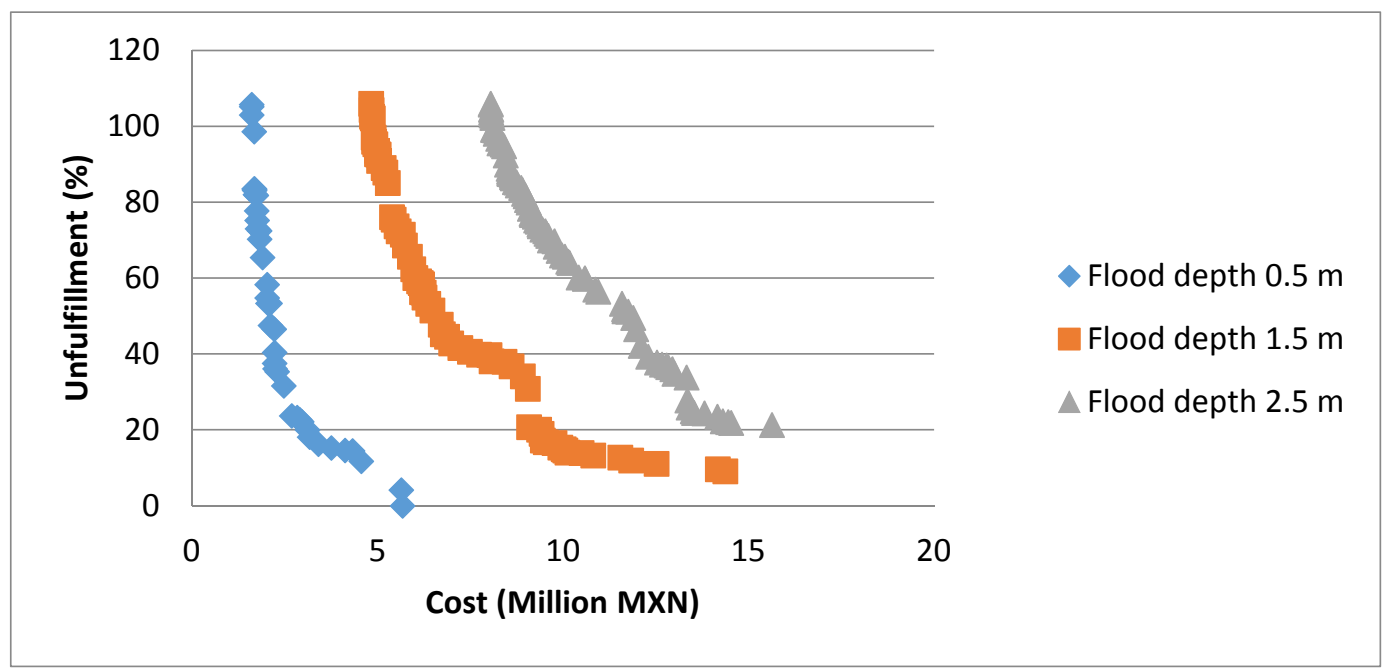

Figure 6. Pareto frontier of the three scenarios for preparedness in Acapulco

The reason the percentage of unfullfillment is beyond $100 \%$ on some low-cost solutions is because of the use of standardised units for distribution. As the number of items unsatisfied is transformed to number of people, if the demand was not fulfilled the requirements could be higher than the actual requirements. For instance, with a shelter demanding food pantries for 50 people, the model would identify the need of 13 food pantries (52 people). But if those food pantries were not shipped, converting them back would represent 52 unsatisfied people, which would be higher than the actual demand per shelter.

Each one of the solutions contains a policy that can be used for preparedness decisions. Table 1 shows an overview of the results from which it can be concluded that only a flood of 0.5 meters could have been managed with current resources to achieve $100 \%$ of demand satisfaction. 
Table 1. Overview of the results of the efficient points of the three scenarios in Acapulco

\begin{tabular}{|c|c|c|c|c|c|c|c|c|c|c|}
\hline \multirow[t]{2}{*}{ Flood } & \multicolumn{2}{|c|}{ Cost (MXN) } & \multirow{2}{*}{$\begin{array}{l}\text { Maximum } \\
\text { agencies }\end{array}$} & \multicolumn{4}{|c|}{ Maximum Fill Rate (\%) } & \multicolumn{2}{|c|}{ Shelters } & \multirow{2}{*}{$\begin{array}{l}\text { Max } \\
\text { DCs }\end{array}$} \\
\hline & Minimum & Maximum & & Food & Med & Health & S.C. & Min & Max & \\
\hline $0.5 \mathrm{~m}$ & $1,609,918.68$ & $5,676,227.86$ & 6 & 100 & 100 & 100 & 100 & 10 & 29 & 8 \\
\hline $1.5 \mathrm{~m}$ & $4,830,802$ & $14,379,448$ & 9 & 76.56 & 34.45 & 100 & 100 & 31 & 79 & 11 \\
\hline $2.5 \mathrm{~m}$ & $8,057,277.04$ & $15,634,537.56$ & 8 & 45.93 & 20.29 & 96.4 & 99.98 & 63 & 92 & 7 \\
\hline
\end{tabular}

None of the three scenarios required the activation of all of the organisations. Even for the couple of solutions obtained under real circumstances activating 9 agencies, the organisation that was not assigned (SEMAR) represents nearly $38 \%$ of the total operative personnel available. Hence, these results show no apparent benefit in sending all of the organisations available to the field.

Available items prepositioned for relief distribution seem insufficient for moderate to catastrophic conditions. In fact, this conclusion was supported by measures taken by Mexican authorities after the flood in 2013, increasing the amount of prepositioned stock in the region from 2,500 to 10,000 food pantries (DICONSA, 2014). Using an analytic tool to test the capabilities of the disaster management system prior to the situation could have identified this shortcoming earlier, and it could be more suitable for future analysis than just considering the number of people served in the most recent event.

\section{MODEL EVALUATION}

Most of the articles in the literature are assuming one organisation owning all resources. The problem being that there are only two scenarios where this is applicable; either each organisation runs their own model and acts accordingly on the results, or resources from all of the organisations available are pooled together leaving the allocation of those resources to other decision mechanisms. The former complicates the possibility of collaboration and allows duplication of efforts, whereas the latter allows the use of sub-optimal solutions for allocation and requires the involvement of every organisation available. In order to test the suitability of both approaches, this article is investigating two scenarios; a scenario where each organisation works independently, and another comparing the results to real decisions assuming Mexican authorities used a coordinated approach in the flood of 2013.

\subsection{Independent decision making}

This section elaborates on the results of an instance assuming each organisation operates disregarding activities and resources from other participants. This approach would be taken by organisations trying to help but unwilling to collaborate with the government. In this case, each one of the actors would run a model to identify the policy that suits them best and they would act independently.

Among the assumptions considered for this instance, partial opening of DCs was allowed and operative personnel was interchangeable. Considering the conditions of the real flood, the model was set to run for 50 iterations of 450 seconds each using the $\varepsilon$-constraint method in GAMS®. Figure 7 
shows the comparison between the best solution in terms of fill rate from each one of the agencies and the Pareto frontier obtained from the system proposed for this instance. None of the agencies seems to be able to deal with the situation independently.

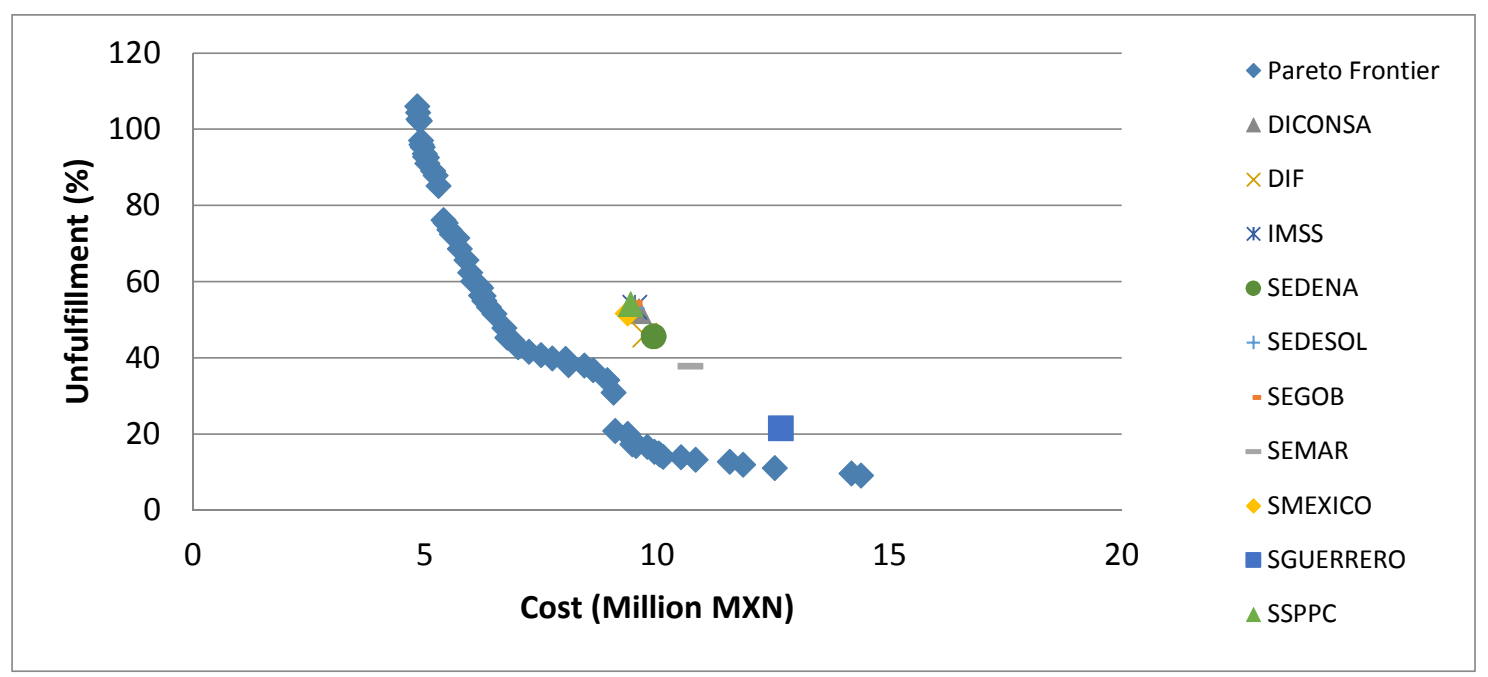

Figure 7. Comparison between coordinated and independent approaches in Acapulco

The importance of cooperation between agencies for different activities plays a major role, as specific resources are only available for certain agencies. In addition, disregarding the decisions taken by other agencies complicates overall operations. Interoperability is essential to provide a better level of service for victims, and this factor becomes more important as the magnitude of the disaster increases.

\subsection{Assessment of the preparedness model under real circumstances}

The ideal way to obtain an evaluation of the model would be to test it in a real situation, something highly complicated as disasters are uncertain and cannot be controlled, making the task impossible (or very unlikely) to be accomplished. The next best thing would be to compare it against the real decisions taken in previous events and compare results.

Keeping record of every decision during a disaster can be complicated given the urgency of other activities. Even though that makes it challenging to obtain information to reconstruct the exact scenario of the situation experienced, in this research extra data was collected from government authorities to assess the results obtained. Details about the management of facilities, relief and human resources were gathered. Figure 8 shows the information obtained in terms of the main choices made by the model. Black squares represent information obtained whereas white squares display information unavailable. Missing data was related to the use of the resources. For instance, there is information about the demand per shelter but not about the origin of it (where people is coming from); or the number of personnel used for each activity but not to what facility they were employed. These decisions can be optimised to provide the best possible outcome authorities could have gotten in the real situation, i.e. the best allocation of resources for their decisions 


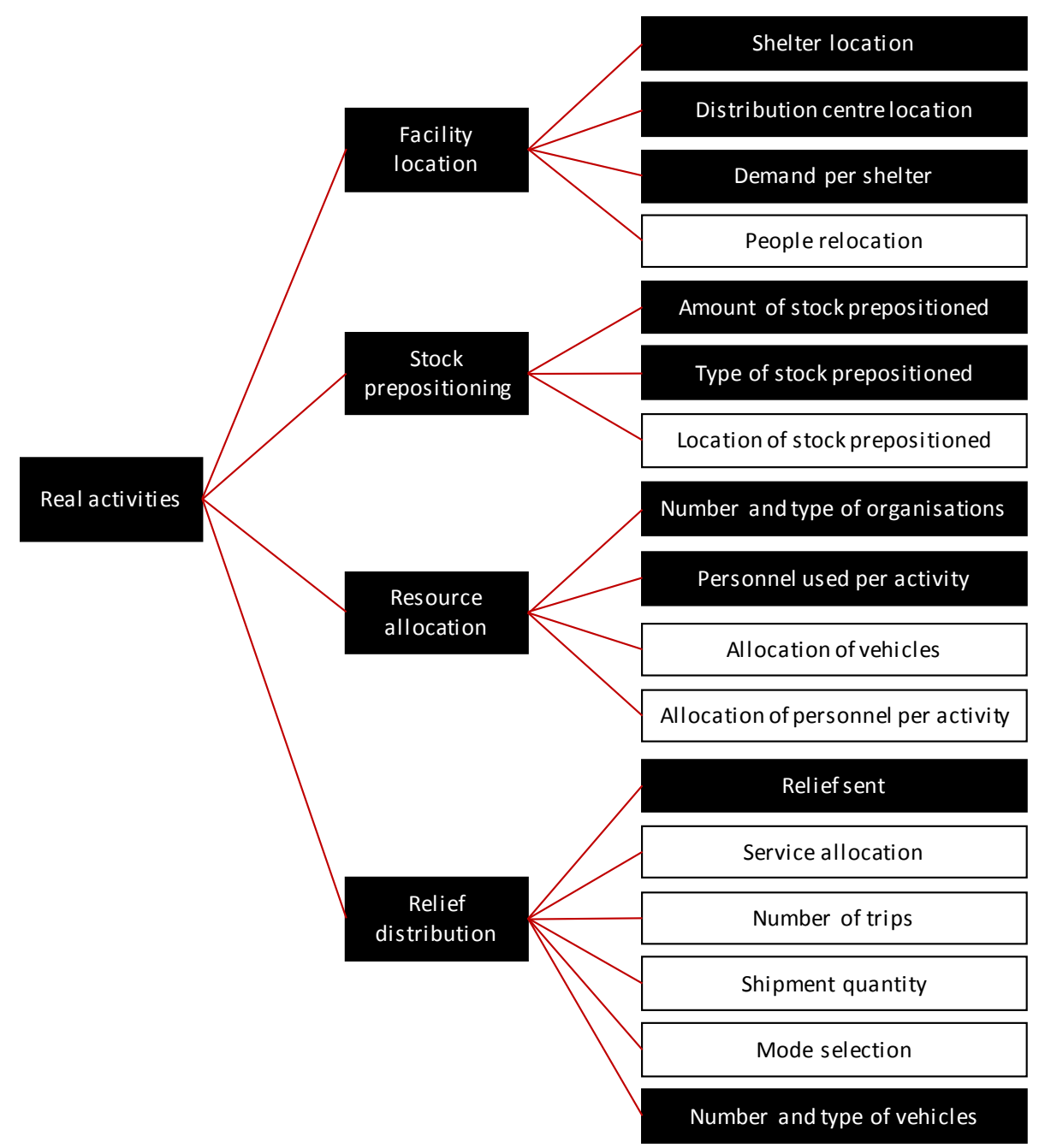

Figure 8. Set of decisions of the preparedness model provided by authorities

Figure 9 shows shelters (small) and DCs (medium) used by authorities in the flood of Acapulco.

There are 6 shelters that seem to be in a flooded area according to the satellite image in Pedrozo-

Acuña et al. (2014), but for comparison facilities reported by authorities were included with perfect connectivity. 
The data obtained from authorities was used incorporating the same assumptions listed for independent decision making. The $\varepsilon$-constraint method and the weighted-sum method were applied for 50 iterations each with a time limit of 450 seconds. The outcome were the 46 non-dominated points which are contrasted in Figure 10 with the Pareto frontier of the results provided by the model.

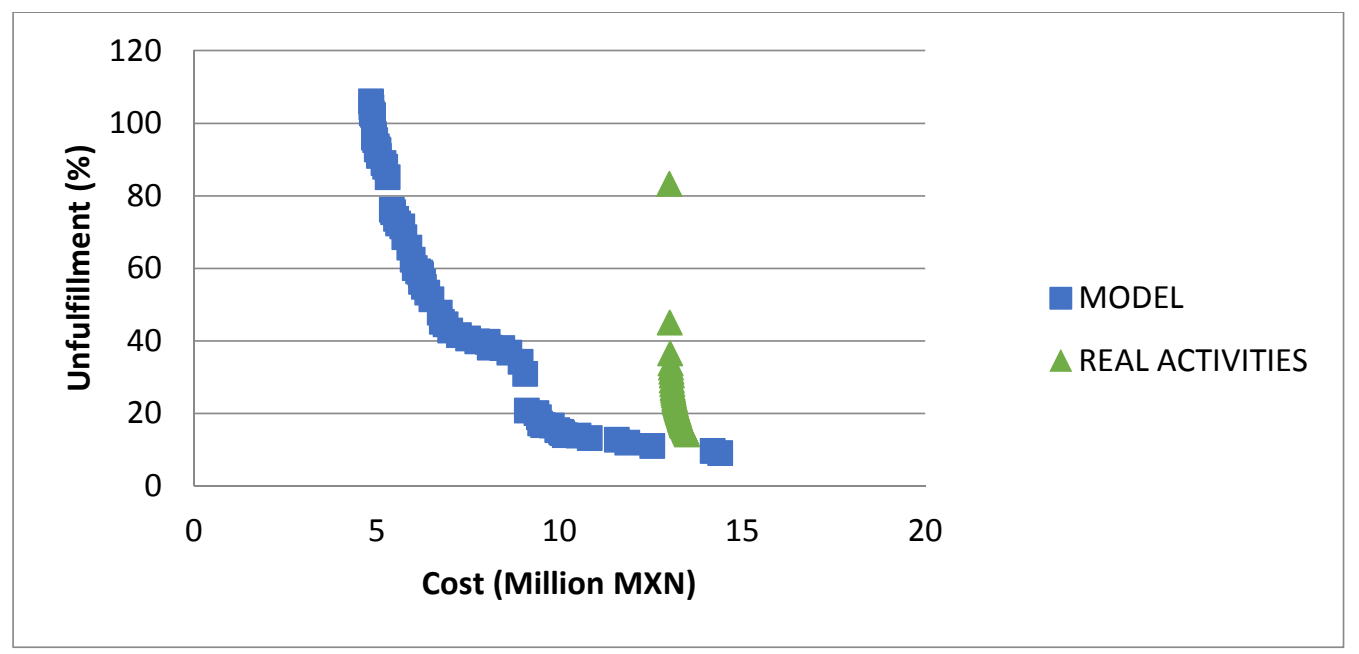

Figure 10. Comparison between the real activities performed by authorities and the results from the system

It seems decisions taken by authorities could have yielded acceptable results, although the solution with the highest fill rate is around 5\% away from the best solution of the model proposed. This solution is costlier than the solution with an equivalent level of service from the system as well. Therefore, better solutions in terms of cost and service can be obtained using the system proposed.

\section{DISCUSSION OF RESULTS}

Results showed that an absence of collaboration can lead to poor level of service even with enough resources for the situation. There is evidence that a) there is no government agency in Mexico capable of dealing with a disaster individually, b) that there is a need for interoperability to delegate and distribute tasks among different actors, and c) that there are potential improvements in both cost and service by adopting a more systemic approach.

The value of the comparison between coordinated and independent decision-making goes beyond just a theoretical proof of the unsuitability of an independent approach, but to emphasise that is a problem that can affect any organisation. It is key for government organisations to collaborate with each other in order to achieve better operations and avoid duplication of efforts or uneven coverage.

The major test for the model was the comparison to the decisions undertaken by authorities in reality. The small variation in cost among solutions of the real instance was because only transportation cost varied (considering all of the other decisions affecting cost were fixed by authorities). However, the range in level of service shows how important is to use resources in the best way possible. 
Table 2 shows a comparison under different metrics between the different instances. Assuming each organisation acts independently from the others, the results were aggregated to see the impact in the overall operations (AGENCIES). The best possible outcome of the instance based on the activities performed by authorities was considered for further analysis (REAL). From the results of the model proposed, the solution with maximum fill rate (MFR) was included to show the capabilities of the model, and another solution from the frontier was chosen to show the concept of trade-off (A1ND54).

Table 2. Comparison of preparedness results for the flood of Acapulco

\begin{tabular}{|c|c|c|c|c|c|c|c|c|c|c|}
\hline \multirow[b]{2}{*}{ Solution } & \multirow[b]{2}{*}{$\begin{array}{c}\text { Cost } \\
(\mathbf{M X N})\end{array}$} & \multirow[b]{2}{*}{ Agencies } & \multicolumn{4}{|c|}{ Fill Rate (\%) } & \multicolumn{2}{|c|}{ Facilities } & \multirow[b]{2}{*}{$\begin{array}{l}\text { Total } \\
\text { trips }\end{array}$} & \multirow{2}{*}{$\begin{array}{c}\text { Evac } \\
\text { Distance } \\
\text { p/person } \\
\text { (km) }\end{array}$} \\
\hline & & & Food & Med & Health & S.C. & Shel & DCs & & \\
\hline A1ND54 & $10,061,802$ & 6 & 76.13 & 33.40 & 99.94 & 99.98 & 42 & 6 & 46 & 16.14 \\
\hline MFR & $14,379,448$ & 9 & 76.56 & 34.41 & 99.92 & 99.96 & 83 & 10 & 101 & 16.01 \\
\hline REAL & $13,542,000$ & 10 & 71.36 & 26.05 & 100 & 98.95 & 56 & 5 & 110 & 13.68 \\
\hline AGENCIES & $15,896,167$ & 10 & 69.99 & 19.25 & 66.98 & 97.02 & 97 & 3 & 28 & 8.45 \\
\hline
\end{tabular}

From the comparison it can be seen that the use and management of organisations was not really justified under the circumstances of the emergency, incurring in higher costs and lower performance. That result supports the idea that having more resources in the field is not guarantee of better operations.

The comparison in terms of fill rate of food, medicines, healthcare and shelter care show that the solutions from the model reach better values. Looking at A1ND54 and MFR the concept of trade-off can be clearly seen. To reach slightly better metrics in terms of food and medicine delivery the decision-maker would have to spend over $\$ 4$ million more, because of the agencies required to achieve that slight difference. However, it is worth mentioning that difference represents satisfying around 188 people more. That is the reason multi-objective optimisation is used, to allow the decision-maker to weight the possibilities and find the best solution according to his/her utility.

AGENCIES delivered the highest cost and lowest fill rates in general. In this case, those fill rates were because of the absence of distribution personnel in agencies with medical supplies, and some resources were wasted in sending relief to the wrong shelters. Shortages of medicines and food highlight the need to look into prepositioning policies used by authorities.

Results from the model open fewer facilities than the actual number opened by authorities ( 56 shelters and 6 DCs) on more than $91 \%$ of the solutions, showing that a number of facilities might have been unnecessary. The average occupancy rate of shelters was $80 \%$, showing appropriate use. There is a 
need to define or upgrade current decision making processes in terms of facility location, as the number of shelters used seem to be inadequate considering the circumstances of the disaster.

Evacuation distance is clearly better in the solution of independent decision-making. The reason is the number of facilities activated, the size and the wide distribution of them. The large value of evacuation distance per person is linked to the extension of the city. As this tool is focused on preparedness, it assumes evacuation could to be performed before the disaster strikes. This approach allows the use of evacuation plans that can handle the distances obtained by the model. The reason these distances are deemed acceptable is because they are incurred just once (or twice when the disaster finishes), whereas relief distribution can be performed for weeks or months, making the location of facilities in terms of that activity highly relevant in the long term.

Considering the preferences of authorities, emphasis is placed in cost and fill rate. In that sense, the model was able to obtain solutions with better fill rates than the other two instances, while keeping competitive costs (lower for the solution selected for analysis). The reason is because, for example, the difference in medicines delivered between the maximum fill rate reached by the model and the real activities performed by authorities represents around 1,092 people. As authorities are very focused on reaching as many people as possible, the model can help achieve that while keeping an eye on cost. Additionally, it is important to emphasise these results were obtained with less organisations involved, using only the right expertise in the field, which can in turn reduce the complexities of logistics operations and allow more visibility among actors.

Despite the fact that the system has not been implemented in practice, the integration of decision factors from authorities and the use of real data for application show the potential benefits of this proposal. From the results obtained it can be seen how the system developed can improve disaster operations in Mexico. Under the setting currently established by authorities, this kind of tool could be a good fit to achieve better operations. The study of the flood of 2013 displayed improvable levels of service accomplished with an oversupply of human resources.

This research is not only addressing a real problem, but it is also providing a solution that can be attractive for the disaster management in countries such as Mexico. For that to happen, the conditions specified in the section about model assumptions and context have to be appropriately analysed. The advantages of the system proposed require a collaborative environment with an overarching decisionmaker capable of coordinating different organisations. Also, there are many challenges associated with joint operations. These should be carefully addressed to be able to extract the expected benefits of the application of these kind of Operational Research models.

Implementation of this system can be enhanced by the incorporation of organisations with pre-existent agreements and relations. Even though the system is capable of supporting any organisation, in reality 
the interoperability between organisations can be a crucial factor for successful operations. Having a set of agreements regarding information sharing, obligations and resources available beforehand can be beneficial for activities in the field. This work is designed to provide a policy before the disaster occurs, with solutions that are useful prior to and immediately after the phenomenon strikes. Under those circumstances, it becomes easier to use organisations already involved. However, the exception can be when the existent pool of actors is deemed insufficient for the situation. In that case support from other organisations can be asked and their inclusion would require mostly sharing data about resources at their disposal, although collaboration without prior agreements can be complex.

There are practical limitations for implementation as well. The system can be used to inform the decision maker about how to manage logistics decisions and direct organisations involved. Nonetheless, data plays a significant role in the application. Most of the information required by the system can be acquired prior to the event and it is in possession of the organisations involved. That data is in the form of inventory of resources available and guidelines. The information should be as accurate and timely available as possible. Regarding data about the circumstances of the flood, the analysis of different scenarios should be used to introduce information in the model resembling the expected conditions. The thorough analysis in the GIS and constant update of prior information is essential to improve the applicability of solutions.

Similarly, it is important to have accurate forecasting tools. Overestimating or underestimating the situation can cause waste of resources or insufficient response. Forecasting methods combined with hydrological analysis can significantly support the quality of the data used and the overall result of the analysis. Additionally, the use of demand estimation methods along with the assessment of the disaster with the GIS analysis can support the use of the system proposed.

Communication issues or obscure information can derive in poor operations. It is important that the leading organisation keeps in contact with other agencies and organisations, particularly once a disaster is expected, to be able to guide their activities. This paper is presenting a solution for initial activities, therefore the use of reliable communication channels between the leading organisation and the rest of the participants can be prepared in advanced to allow the results of the system to be able to support field operations.

The implementation of the system requires an analyst for application and analysis of results. The analyst requires knowledge of GIS and optimisation to deliver informed results to the decision-maker. In terms of solution time, for large-scale disasters it would be important to apply the system as soon as possible because it could require significant solution time.

Discussing the practical value of the system proposed, it has the possibility of performing scenario planning, so authorities can plan under what situations national authorities should take part, and under which conditions only local authorities are needed. That can speed-up the request process for help 
from higher authorities and allow swift deployment to manage the situation. Using different scenarios authorities can also identify areas for improvement in the system, test the operational boundaries and develop pre-designed plans under different circumstances.

Avoiding overcrowding and duplication of efforts by using the proposed model as an enabler for coordination is a relevant note. Coordination is a complex topic that requires efforts at different levels to be tackled. This article is proposing a system able to provide a setting to reduce ambiguity and facilitate the conditions for joint operations.

In disaster management there are different participant organisations with different resources. Therefore, there is a need to change the current practice of incorporating only one participant in optimisation models. One of the main outcomes of this research is that it is not about sending every organisation available, but the right organisations. The results show how better performances can be achieved with less resources, something that can be very valuable in the field and that can change current practices.

\section{CONCLUSIONS}

Taking advantage of the potential of OR to tackle relevant real-world problems, this research proposed a method for flood preparedness focusing on the application of a multi-organisational approach to facility location, stock prepositioning, distribution and resource allocation; a perspective neglected until now. This research pointed out the value of considering several actors in models for humanitarian logistics to provide a more comprehensive tool for decision-makers. The optimised scenario of the activities performed by authorities was dominated by the Pareto frontier of the system developed. This indicates the existence of room for improvement for the decisions currently being made in practice by incorporating a preparedness system as the one proposed.

Using real data, the results highlight that having more resources in the field does not guarantee to perform better operations. It is having the right resources in the field what matters. The system designed was able to improve the outcome of real activities performed by authorities with fewer organisations involved. The model presented here is the first of its kind to be able to handle different organisations and decide, based on their resources, which ones ought to be activated for logistics activities. That can prevent wastage of resources and enhance coordination.

As each organisation has limited capacity, interoperability is crucial for disaster management. The model allows the user to find the most advantageous combination of resources and to complement capabilities, thereby making it possible to include multiple participants in disaster management.

Exploring the capabilities of the current disaster management system by testing the operational boundaries can avoid an unjustified overconfidence on capacity (e.g. facilities, supply) planning for future events. This model is able to test such boundaries and identify areas of improvement for the 
decision maker and/or the organisations. Moreover, scenario analysis can be performed using this model to have pre-designed disaster management policies under different circumstances.

Although independent participation from government organisations can seem unrealistic, under real circumstances the complications of coordination can lead to some of them acting on their own. This research strengthens the idea of the need of collaboration among government organisations and how the lack of it can have significant impact in the outcome of the situation.

Discussing the transference of this model to a different context, the requirements would be based mostly in the structure of the disaster management system. The existence of a leading organisation is important to oversee and direct the efforts of different individual participants. The organisations involved would require a link to the leading organisation, namely a government, and have pre-defined agreements for operation. A communication hub would be important to ease sharing information and facilitating the collaboration among the different participants. The other requirements would be the existence of agreements with suppliers, financial instruments for funding disaster operations, the existence of geographical information, the inclusion of organisations with vehicles available or the inclusion of transportation companies, standardised units for distribution, and a prepositioning policy for immediate deployment.

Thinking about response activities, the ideas from this paper could be used to develop a response model to provide support for the entire duration of the flood, with a set of modifications. A static model, as the one proposed here, could not be able to consider the evolution of events through time (e.g. which shelters were served before). Less attention should be placed to facility location and more to facility management. Also, inventory decisions should be introduced and the equity measure should be incorporated across periods. Future research can be focused on the development of such model.

There are still many challenges to be addressed. Even though results from the evacuation distance were somehow close to the benchmark, it is still a very important concern. Coupling the system designed with traffic assignment for evacuation can be very useful. The incorporation of routing systems would be a useful addition. The model as it is designed is not able to handle differences in hierarchy between organisations, and the use of hierarchical models is a promising venue.

\section{ACKNOWLEDGMENTS}

The corresponding author wants to acknowledge financial support from the Consejo Nacional de Ciencia y Tecnologia and Aston University for the development of this research.

The authors would want to thank the reviewers of this paper for their time and insightful comments to improve the quality of the paper. 


\section{REFERENCES}

Abounacer, R., Rekik, M., \& Renaud, J. (2014). An exact solution approach for multi-objective location-transportation problem for disaster response. Computers \& Operations Research, 41(0), 83-93. doi: http://dx.doi.org/10.1016/i.cor.2013.08.001

Adıvar, B., \& Mert, A. (2010). International disaster relief planning with fuzzy credibility. [Article]. Fuzzy Optimization \& Decision Making, 9(4), 413-433. doi: 10.1007/s10700-010-9088-8

Alem, D., Clark, A., \& Moreno, A. (2016). Stochastic network models for logistics planning in disaster relief. European Journal of Operational Research, 255(1), 187-206. doi: http://dx.doi.org/10.1016/j.ejor.2016.04.041

Alexander, D. (2015). Evaluation of civil protection programmes, with a case study from Mexico. Disaster Prevention and Management: An International Journal, 24(2), 263-283. doi: 10.1108/DPM-12-2014-0268

Altay, N. (2013). Capability-based resource allocation for effective disaster response. IMA Journal of Management Mathematics, 24(2), 253-266. doi: 10.1093/imaman/dps001

Altay, N., \& Green, W. G. (2006). OR/MS research in disaster operations management. European Journal of Operational Research, 175(1), 475-493. doi: 10.1016/j.ejor.2005.05.016

Arora, H., Raghu, T. S., \& Vinze, A. (2010). Resource allocation for demand surge mitigation during disaster response. [Article]. Decision Support Systems, 50(1), 304-315. doi: 10.1016/j.dss.2010.08.032

Auf der Heide, E. (1989). Disaster response: principles of preparation and coordination. St. Louis, MO: Mosby, Incorporated.

Balcik, B., Beamon, B. M., Krejci, C. C., Muramatsu, K. M., \& Ramirez, M. (2010). Coordination in humanitarian relief chains: Practices, challenges and opportunities. [Article]. International Journal of Production Economics, 126(1), 22-34. doi: 10.1016/j.ijpe.2009.09.008

Barbarosoğlu, G., Özdamar, L., \& Çevik, A. (2002). Decision Aiding: An interactive approach for hierarchical analysis of helicopter logistics in disaster relief operations. [Article]. European Journal of Operational Research, 140, 118-133. doi: 10.1016/s0377-2217(01)00222-3

Barzinpour, F., \& Esmaeili, V. (2014). A multi-objective relief chain location distribution model for urban disaster management. The International Journal of Advanced Manufacturing Technology, 70(5-8), 1291-1302. doi: 10.1007/s00170-013-5379-x

Beamon, B. M., \& Balcik, B. (2008). Performance measurement in humanitarian relief chains. [Article]. International Journal of Public Sector Management, 21(1), 4-25. doi: 10.1108/09513550810846087

Bertrand, J. W. M., \& Fransoo, J. C. (2002). Operations management research methodologies using quantitative modeling. International Journal of Operations \& Production Management, 22(2), 241-264. doi: doi:10.1108/01443570210414338

Bish, D. R., \& Sherali, H. D. (2013). Aggregate-level demand management in evacuation planning. European Journal of Operational Research, 224(1), 79-92. doi: 10.1016/j.ejor.2012.07.036

Bozorgi-Amiri, A., Jabalameli, M., Alinaghian, M., \& Heydari, M. (2012). A modified particle swarm optimization for disaster relief logistics under uncertain environment. The International Journal of Advanced Manufacturing Technology, 60(1-4), 357-371. doi: 10.1007/s00170-0113596-8

Bozorgi-Amiri, A., Jabalameli, M. S., \& Mirzapour Al-e-Hashem, S. M. J. (2011). A multi-objective robust stochastic programming model for disaster relief logistics under uncertainty. $O R$ Spectrum, 1-29. doi: 10.1007/s00291-011-0268-x

Bretschneider, S., \& Kimms, A. (2012). Pattern-based evacuation planning for urban areas. European Journal of Operational Research, 216(1), 57-69. doi: 10.1016/j.ejor.2011.07.015

Campbell, A. M., \& Jones, P. C. (2011). Prepositioning supplies in preparation for disasters. European Journal of Operational Research, 209(2), 156-165. doi: 10.1016/j.ejor.2010.08.029 
Caunhye, A. M., Nie, X., \& Pokharel, S. (2012). Optimization models in emergency logistics: A literature review. Socio-Economic Planning Sciences, 46(1), 4-13. doi: 10.1016/j.seps.2011.04.004

CENAPRED. (2014). Information request \#0413000010014 (pp. 8): Centro Nacional para la Prevención de Desastres.

Chang, M.-S., Tseng, Y.-L., \& Chen, J.-W. (2007). A Scenario Planning Approach for the Flood Emergency Logistics Preparation Problem under Uncertainty. Transportation Research: Part E: Logistics and Transportation Review, 43(6), 737-754. doi: http://www.sciencedirect.com/science/journal/13665545

Chen, A. Y., Peña-Mora, F., \& Ouyang, Y. (2011). A collaborative GIS framework to support equipment distribution for civil engineering disaster response operations. Automation in Construction, 20(5), 637-648. doi: http://dx.doi.org/10.1016/j.autcon.2010.12.007

De Leeuw, S., Vis, I. F. A., \& Jonkman, S. N. (2012). Exploring Logistics Aspects of Flood Emergency Measures. Journal of Contingencies and Crisis Management, 20(3), 166-179. doi: 10.1111/j.1468-5973.2012.00667.x

DICONSA. (2014). Information request \#2015000000614: DICONSA.

Drabek, T. E., \& McEntire, D. A. (2003). Emergent phenomena and the sociology of disaster: Lessons, trends and opportunities from the research literature. [Article]. Disaster Prevention and Management, 12(2), 97-112. doi: 10.1108/09653560310474214

Edrissi, A., Poorzahedy, H., Nassiri, H., \& Nourinejad, M. (2013). A multi-agent optimization formulation of earthquake disaster prevention and management. European Journal of Operational Research, 229(1), 261-275. doi: http://dx.doi.org/10.1016/i.ejor.2013.03.008

Esmaeili, V., \& Barzinpour, F. (2014). Integrated decision making model for urban disaster management: A multi-objective genetic algorithm approach. International Journal of Industrial Engineering Computations, 5(1), 55-70. doi: 10.5267/j.ijiec.2013.08.004

Esteves, L. S. (2013). Consequences to flood management of using different probability distributions to estimate extreme rainfall. [Article]. Journal of Environmental Management, 115, 98-105. doi: 10.1016/j.jenvman.2012.11.013

Falasca, M., \& Zobel, C. (2012). An optimization model for volunteer assignments in humanitarian organizations. Socio-Economic Planning Sciences, 46(4), 250-260. doi: http://dx.doi.org/10.1016/j.seps.2012.07.003

Galindo, G., \& Batta, R. (2013). Review of Recent Developments in OR/MS Research in Disaster Operations Management. European Journal of Operational Research(0). doi: http://dx.doi.org/10.1016/j.ejor.2013.01.039

García, N., Méndez, K., Reyes, R., \& Marin, R. (2015). Impacto Socioeconómico de los Principales Desastres Ocurridos en la República Mexicana en 2013. México, D.F.: CENAPRED.

Gillespie, D. F. (1991). Coordinating community resources. In T. E. D. G. J. Hoetmer (Ed.), Emergency management: Principles and practice for local government (pp. pp. 55-78). Washington, DC: City Management Association.

Holguín-Veras, J., Jaller, M., \& Wachtendorf, T. (2012). Comparative performance of alternative humanitarian logistic structures after the Port-au-Prince earthquake: ACEs, PIEs, and CANs. Transportation Research Part A: Policy and Practice, 46(10), 1623-1640. doi: http://dx.doi.org/10.1016/i.tra.2012.08.002

Huang, K., Jiang, Y., Yuan, Y., \& Zhao, L. (2015). Modeling multiple humanitarian objectives in emergency response to large-scale disasters. Transportation Research Part E: Logistics and Transportation Review, 75(0), 1-17. doi: http://dx.doi.org/10.1016/j.tre.2014.11.007

INEGI. (2010a). México en Cifras Retrieved June 5th, 2014, from http://www.inegi.org.mx/movil/MexicoCifras/mexicoCifras.aspx?em=12001\&i=e

INEGI. (2010b). SCINCE versión 05/2012 para escritorio. Retrieved from http://www.inegi.org.mx/est/scince/scince2010.aspx 
Kourgialas, N. N., \& Karatzas, G. P. (2011). Flood management and a GIS modelling method to assess flood-hazard areas-a case study. Hydrological Sciences Journal, 56(2), 212-225. doi: 10.1080/02626667.2011.555836

Kovács, G., \& Spens, K. (2009). Identifying challenges in humanitarian logistics. [Article]. INTERNATIONAL JOURNAL OF PHYSICAL DISTRIBUTION AND LOGISTICS MANAGEMENT, 39(6), 506-528. doi: 10.1108/09600030910985848

Kunz, N., \& Reiner, G. (2012). A meta-analysis of Humanitarian Logistics research. Journal of Humanitarian Logistics and Supply Chain Management 2(2), 32.

Liberatore, F., Pizarro, C., de Blas, C. S., Ortuño, M. T., \& Vitoriano, B. (2013). Uncertainty in Humanitarian Logistics for Disaster Management. A Review. In B. Vitoriano, J. Montero \& D. Ruan (Eds.), Decision Aid Models for Disaster Management and Emergencies (Vol. 7, pp. 4574): Atlantis Press.

Liebscher, S., Kirschstein, T., \& Becker, C. (2012). The flood algorithm-a multivariate, selforganizing-map-based, robust location and covariance estimator. Statistics and Computing, 22(1), 325-336. doi: 10.1007/s11222-011-9250-3

Lim, M. B., Lim Jr, H., \& Piantanakulchai, M. (2013). Factors Affecting Flood Evacuation Decision and Its Implication to Transportation Planning. [Factors Affecting Flood Evacuation Decision and Its Implication to Transportation Planning]. Journal of the Eastern Asia Society for Transportation Studies, 10(0), 163-177. doi: 10.11175/easts.10.163

Lindell, M. K., Kang, J. E., \& Prater, C. S. (2011). The logistics of household hurricane evacuation. [journal article]. Natural Hazards, 58(3), 1093-1109. doi: 10.1007/s11069-011-9715-x

Lu, C. C. (2013). Robust weighted vertex p-center model considering uncertain data: An application to emergency management. European Journal of Operational Research, 230(1), 113-121. doi: 10.1016/j.ejor.2013.03.028

Martin, K. (1993). Modeling the impact of sea level rise in Narraganset Bay, Rhode Island. In Worcester (Ed.), Applications in Coastal Research and Management (pp. 59-61). Geneva: UNITAR.

Maya Duque, P. A., Dolinskaya, I. S., \& Sörensen, K. (2016). Network repair crew scheduling and routing for emergency relief distribution problem. European Journal of Operational Research, 248(1), 272-285. doi: http://dx.doi.org/10.1016/i.ejor.2015.06.026

Merz, R., \& Blöschl, G. (2003). A process typology of regional floods. Water Resources Research, 39(12), n/a-n/a. doi: 10.1029/2002wr001952

Mete, H. O., \& Zabinsky, Z. B. (2010). Stochastic optimization of medical supply location and distribution in disaster management. International Journal of Production Economics, 126(1), 76-84. doi: 10.1016/j.ijpe.2009.10.004

Miettinen, K. (2008). Introduction to Multiobjective Optimization: Noninteractive Approaches. In J. Branke, K. Deb, K. Miettinen \& R. Słowiński (Eds.), Multiobjective Optimization. [electronic resource] : Interactive and Evolutionary Approaches: Berlin, Heidelberg : Springer Berlin Heidelberg, 2008.

Nagarajan, M., Shaw, D., \& Albores, P. (2012). Innovative Applications of O.R.: Disseminating a warning message to evacuate: A simulation study of the behaviour of neighbours. [Article]. European Journal of Operational Research, 220, 810-819. doi: 10.1016/j.ejor.2012.02.026

Naji-Azimi, Z., Renaud, J., Ruiz, A., \& Salari, M. (2012). A covering tour approach to the location of satellite distribution centers to supply humanitarian aid. European Journal of Operational Research, 222(3), 596-605. doi: 10.1016/j.ejor.2012.05.001

Nolte, I. M., Martin, E. C., \& Boenigk, S. (2012). Cross-Sectoral Coordination of Disaster Relief. [Article]. Public Management Review, 14(6), 707-730. doi: 10.1080/14719037.2011.642629

Noyan, N. (2012). Risk-averse two-stage stochastic programming with an application to disaster management. Computers \& Operations Research, 39(3), 541-559. doi: 10.1016/j.cor.2011.03.017 
Özdamar, L., \& Ertem, M. A. (2015). Models, solutions and enabling technologies in humanitarian logistics. European Journal of Operational Research, 244(1), 55-65. doi: http://dx.doi.org/10.1016/i.ejor.2014.11.030

Pedrozo-Acuña, A., Breña-Naranjo, J. A., \& Domínguez-Mora, R. (2014). The hydrological setting of the 2013 floods in Mexico. Weather, 69(11), 295-302. doi: 10.1002/wea.2355

Pidd, M., De Silva, F. N., \& Eglese, R. W. (1996). A simulation model for emergency evacuation. European Journal of Operational Research, 90(3), 413-419. doi: 10.1016/03772217(95)00112-3

Rawls, C. G., \& Turnquist, M. A. (2010). Pre-positioning of emergency supplies for disaster response. Transportation Research Part B: Methodological, 44(4), 521-534. doi: 10.1016/j.trb.2009.08.003

Rawls, C. G., \& Turnquist, M. A. (2011). Pre-positioning Planning for Emergency Response with Service Quality Constraints. OR Spectrum, 33(3), 481-498. doi: http://www.springerlink.com/link.asp?id=102498

Rawls, C. G., \& Turnquist, M. A. (2012). Pre-positioning and dynamic delivery planning for short-term response following a natural disaster. [Article]. Socio-Economic Planning Sciences, 46(1), 4654. doi: 10.1016/j.seps.2011.10.002

Renkli, Ç., \& Duran, S. (2015). Pre-Positioning Disaster Response Facilities and Relief Items. Human and Ecological Risk Assessment: An International Journal, 21(5), 1169-1185. doi: 10.1080/10807039.2014.957940

Rennemo, S. J., Rø, K. F., Hvattum, L. M., \& Tirado, G. (2014). A three-stage stochastic facility routing model for disaster response planning. Transportation Research Part E: Logistics and Transportation Review, 62(0), 116-135. doi: http://dx.doi.org/10.1016/j.tre.2013.12.006

Rodríguez-Espíndola, O., \& Gaytán, J. (2015). Scenario-based preparedness plan for floods. Natural Hazards, 76(2), 1241-1262. doi: 10.1007/s11069-014-1544-2

Saadatseresht, M., Mansourian, A., \& Taleai, M. (2009). Evacuation planning using multiobjective evolutionary optimization approach. European Journal of Operational Research, 198(1), 305314. doi: http://dx.doi.org/10.1016/j.ejor.2008.07.032

Salmeron, J., \& Apte, A. (2010). Stochastic Optimization for Natural Disaster Asset Prepositioning. PRODUCTION AND OPERATIONS MANAGEMENT, 19(5), 561-574.

Santos-Reyes, J., \& Beard, A. N. (2011). Applying the SDMS Model to the Analysis of the Tabasco Flood Disaster in Mexico. [Article]. Human \& Ecological Risk Assessment, 17(3), 646-677. doi: 10.1080/10807039.2011.571099

Savas, E. S. (1978). ON EQUITY IN PROVIDING PUBLIC SERVICES. [Article]. Management Science, 24(8), 800-808.

SEGOB. (2006). ACUERDO por el que se emite el Manual de Organización y Operación del Sistema Nacional de Protección Civil. México: Retrieved from

http://www.proteccioncivil.gob.mx/work/models/ProteccionCivil/Resource/6/1/images/mo osnpc.pdf.

Sheu, J.-B. (2014). Post-disaster relief-service centralized logistics distribution with survivor resilience maximization. Transportation Research Part B: Methodological, 68(0), 288-314. doi: http://dx.doi.org/10.1016/i.trb.2014.06.016

SSPPC. (2013). Refugios Temporales 2013 Región Acapulco Retrieved 29 September 2014, from http://i.guerrero.gob.mx/uploads/2013/05/refugios-temporales-2013-region-Acapulco.pdf

Tofighi, S., Torabi, S. A., \& Mansouri, S. A. (2016). Humanitarian logistics network design under mixed uncertainty. European Journal of Operational Research, 250(1), 239-250. doi: http://dx.doi.org/10.1016/j.ejor.2015.08.059

Tomlin, C. D. (1991). Cartographic modelling. In P. Longley (Ed.), Geographic information systems and science: Hoboken, N.J. : John Wiley, 1991. 1st ed.

UNISDR. (2009). Reducing Disaster Risks through Science: Issues and Actions. The full report of the ISDR Scientific and Technical Committee 2009 (pp. 23): United Nations. 
USGS. (2010). HydroSHEDS Retrieved 10 April 2011, from

http://gisdata.usgs.gov/website/HydroSHEDS

Ward, P. J., de Moel, H., Aerts, J. C. J. H., \& Glade, T. (2011). How are flood risk estimates affected by the choice of return-periods? Natural Hazards \& Earth System Sciences, 11(12), 3181.

Wenger, D., Quarantelli, E. L., \& Dynes, R. (1986). Disaster Analysis: Emergency Management Offices And Arrangements (pp. 136). Delaware: UNIVERSITY OF DELAWARE, DISASTER RESEARCH CENTER

Wex, F., Schryen, G., Feuerriegel, S., \& Neumann, D. (2014). Emergency response in natural disaster management: Allocation and scheduling of rescue units. European Journal of Operational Research, 235(3), 697-708. doi: http://dx.doi.org/10.1016/j.ejor.2013.10.029

Yi, W., \& Ozdamar, L. (2007). A dynamic logistics coordination model for evacuation and support in disaster response activities. European Journal of Operational Research, 127(3), 1177-1193. 